\title{
Mortality of the 'Golden Generation': What can the ONS Longitudinal Study tell us?
}

Shayla Goldring, Nigel Henretty, Julie Mills, Kate Johnson and Steve Smallwood

\section{Abstract}

It is well documented that the generations born around 1930 are consistently exhibiting higher rates of mortality improvement than the generations either side of them. There is currently no evidence that these differentials are declining. In current ONS National Population Projections, it is assumed that these cohorts will continue to experience higher rates of improvement. However, it is not yet precisely clear why this is so. This article details preliminary research carried out using the ONS Longitudinal Study to try to understand better why the members of the generation born around 1930 have been enjoying higher rates of mortality improvement throughout their adult life. 


\section{Introduction}

Peak levels of mortality improvement appear to be a special feature of the generations born in the decade centred around 1930 (those born between 1925 and 1934), known as the 'golden cohort $^{1,2}$. The term 'cohort effect' has been used where a specific birth cohort has experienced a noticeably different pattern of mortality rate improvement over time from that of other cohorts ${ }^{3}$. The mortality experiences of the 'golden cohort' are the subject of much interest for demographers, actuaries and financiers. It is not understood precisely why the members of the generation born around the early 1930s have been enjoying higher rates of mortality improvement throughout their adult life than preceding generations, or why the rate of improvement slowed down for following generations ${ }^{4}$. It may, however, be relevant that this generation benefited from a combination of better childhood health, improving preventive and treatment regimes for infectious diseases affecting young and middle-aged adults, and, in later middle-age, improvements in the treatment of circulatory diseases. This generation was also subject to rationing in their adolescent and early adult years (between 1940 and 1954) which, across the whole population, may have improved general health during childhood and later.

Mortality is an important factor in determining the size and age distribution of the population in the future. The current mortality projections methodology involves projecting rates by cohort for older generations, but by age for younger generations where there is no evidence of a cohort effect taking place. Understanding what is causing the significant decrease in mortality for the generation born between 1925 and 1934 is particularly important for forecasting the population at older ages. Using the ONS Longitudinal Study (ONS LS) we may be able to determine whether there are social and economic differences in the cohorts born in the first half of the twentieth century that may explain the high rates of mortality improvement observed for those born between 1925 and 1934.

\section{Background}

The average annualised rate of improvement in age standardised mortality rates for ages 0-99 over the period 1911-2008 was 1.2 per cent per year for both men and women. Box 1 explains how the mortality rates used in this article have been calculated. Tables $1 \mathbf{a}$ and $\mathbf{1 b}$ show the annualised improvement in age-standardised mortality rates over successive ten year periods between 1951 and 2008 for men and women respectively, in five year age groups. Mortality improvements for children and teenagers are not included in these tables because of the relatively small numbers of deaths occurring at these ages. The shaded areas show the age groups which have experienced greatest mortality improvements over each ten year period between decennial life tables ${ }^{5}$. Table 1a shows that between 1961 and 1971, mortality rates for males improved the most for those aged 30 to 34 (1.6 per cent per year). The age groups exhibiting the most rapid mortality improvements have become successively older in later periods. For example, over the next ten year period, 1971 to 1981 , mortality rates for males improved the most for those aged 40 to 44 (2.2 per cent per year). The resulting pattern suggests that the highest rate of improvements have been experienced by the same groups as they age through time, and broadly reflects the mortality experience of the cohort born between 1926 and 1934, up to the most recent period, 2001 to 2008 (the latest year for which data are available). Similar patterns for females in the same cohorts are shown in Table $1 \mathrm{~b}$. 


\section{Table 1a Rate of annualised improvement in age-standardised} mortality rates, men, England and Wales (per cent)*

\begin{tabular}{lrrrrrr}
\hline $\begin{array}{c}\text { Age } \\
\text { group }\end{array}$ & $\begin{array}{c}\mathbf{1 9 5 1} \\
\text { to } \\
\mathbf{1 9 6 1}\end{array}$ & $\begin{array}{c}\mathbf{1 9 6 1} \\
\text { to } \\
\mathbf{1 9 7 1}\end{array}$ & $\begin{array}{c}\mathbf{1 9 7 1} \\
\text { to } \\
\mathbf{1 9 8 1}\end{array}$ & $\begin{array}{c}\mathbf{1 9 8 1} \\
\text { to } \\
\mathbf{1 9 9 1}\end{array}$ & $\begin{array}{c}\mathbf{1 9 9 1} \\
\text { to } \\
\mathbf{2 0 0 1}\end{array}$ & $\begin{array}{c}\mathbf{2 0 0 1} \\
\text { to } \\
\mathbf{2 0 0 8}\end{array}$ \\
\hline $20-24$ & 1.8 & 1.3 & 1.4 & -0.2 & 1.0 & 3.2 \\
$25-29$ & 3.5 & 1.4 & 0.6 & -0.4 & 0.1 & 1.8 \\
$30-34$ & 2.7 & 1.6 & 1.4 & -0.2 & -0.6 & 0.7 \\
$35-39$ & 2.2 & 1.1 & 1.8 & -0.1 & 0.5 & -0.1 \\
$40-44$ & 2.0 & 0.0 & 2.2 & 1.4 & 0.9 & 0.3 \\
$45-49$ & 1.8 & -0.4 & 2.1 & 2.5 & 1.0 & 1.7 \\
$50-54$ & 1.2 & 0.2 & 1.6 & 3.0 & 2.2 & 1.4 \\
$55-59$ & 0.6 & 0.8 & 1.2 & 3.1 & 2.7 & 1.8 \\
$60-64$ & 0.2 & 0.8 & 1.4 & 2.4 & 3.2 & 2.9 \\
$65-69$ & 0.1 & 0.3 & 1.7 & 1.8 & 3.6 & 2.9 \\
$70-74$ & 0.2 & 0.1 & 1.5 & 1.8 & 2.8 & 4.0 \\
$75-79$ & 0.5 & 0.4 & 0.9 & 1.8 & 2.2 & 3.7 \\
$80-84$ & 0.9 & 0.7 & 0.5 & 1.7 & 1.9 & 2.6 \\
$85-89$ & 1.3 & 0.8 & 0.5 & 1.4 & 1.1 & 2.5 \\
$90-94$ & 1.6 & 0.6 & 0.8 & 0.8 & 0.7 & 2.3 \\
$95-99$ & 1.8 & -0.1 & 1.2 & -0.2 & 0.4 & 1.4 \\
\hline
\end{tabular}

Note: *Source: Mortality rates from successive English Life Tables and the Interim Life Table for England and Wales for 2008, standardised using the 2001 mid-year population estimates. Mortality rates are based on three years of data centred on the year in question.

Table $1 \mathrm{~b} \quad$ Rate of annualised improvement in age-standardised mortality rates, women, England and Wales (per cent)*

\begin{tabular}{llllclll}
\hline $\begin{array}{l}\text { Age } \\
\text { group }\end{array}$ & $\begin{array}{c}\mathbf{1 9 5 1} \\
\text { to } \\
\mathbf{1 9 6 1}\end{array}$ & $\begin{array}{c}\mathbf{1 9 6 1} \\
\text { to } \\
\mathbf{1 9 7 1}\end{array}$ & $\begin{array}{c}\mathbf{1 9 7 1} \\
\text { to } \\
\mathbf{1 9 8 1}\end{array}$ & $\begin{array}{c}\mathbf{1 9 8 1} \\
\text { to } \\
\mathbf{1 9 9 1}\end{array}$ & $\begin{array}{c}\mathbf{1 9 9 1} \\
\text { to } \\
\mathbf{2 0 0 1}\end{array}$ & $\begin{array}{c}\mathbf{2 0 0 1} \\
\text { to }\end{array}$ \\
\hline $20-24$ & 6.4 & 0.6 & 2.0 & 1.1 & 1.1 & 2.4 \\
$25-29$ & 6.1 & 2.0 & 1.4 & 1.7 & 0.7 & 0.6 \\
$30-34$ & 4.4 & 2.1 & 1.6 & 1.5 & 0.6 & 0.4 \\
$35-39$ & 2.9 & 1.7 & 2.0 & 1.3 & 0.9 & 1.2 \\
$40-44$ & 2.1 & 0.7 & 2.4 & 2.0 & 0.9 & 0.9 \\
$45-49$ & 1.8 & -0.1 & 2.2 & 2.3 & 1.1 & 1.7 \\
$50-54$ & 1.7 & -0.1 & 1.3 & 2.6 & 1.3 & 1.6 \\
$55-59$ & 1.6 & 0.3 & 0.6 & 2.3 & 2.0 & 1.8 \\
$60-64$ & 1.5 & 0.8 & 0.5 & 1.4 & 2.9 & 2.0 \\
$65-69$ & 1.3 & 1.0 & 1.0 & 0.9 & 2.8 & 2.6 \\
$70-74$ & 1.3 & 1.1 & 1.4 & 1.1 & 2.0 & 3.1 \\
$75-79$ & 1.4 & 1.2 & 1.5 & 1.5 & 1.4 & 2.9 \\
$80-84$ & 1.4 & 1.4 & 1.2 & 1.9 & 1.1 & 2.0 \\
$85-89$ & 1.2 & 1.3 & 0.8 & 2.1 & 0.5 & 1.9 \\
$90-94$ & 0.8 & 1.1 & 1.0 & 1.5 & 0.0 & 1.3 \\
$95-99$ & 0.2 & 0.2 & 2.1 & 0.3 & -0.3 & 0.5 \\
\hline
\end{tabular}

Note: *Source: Mortality rates from successive English Life Tables and the Interim Life Table for England and Wales for 2008, standardised using the 2001 mid-year population estimates. Mortality rates are based on three years of data centred on the year in question. 
The heat charts (Figures $\mathbf{1 a}$ and $\mathbf{1 b}$ ) show annual percentage change in smoothed mortality rates for the years 1913 to 2008 . Heat charts are two-dimensional contour maps used to visualise large matrices, in particular demographic events, diagrammatically. In this case, time-series annual mortality improvements are categorised into bands and each band is given a colour to show, for every data point, the annual improvement in mortality for each year along the $x$-axis and each age along the $y$-axis. The darkest shades of brown represent the largest improvements in mortality and the shades of blue represent worsening mortality rates. The years between 1913 and 1960 are characterised by alternating periods of negative rates of improvement (worsening mortality rates) particularly for men in their 20 s and 30 s, followed by periods of rapid improvement. The periods showing negative rates of improvement for both men and women coincide with the First World War (1914-18), the influenza pandemic (1918-1921), the Great Depression (commencing in 1929) and the Second World War (1939-45). Men are also shown to have experienced a period of negative improvement in mortality rates around 1955; this may be a result of high smoking uptake for men earlier in the century. From the mid-1950s onwards, the pattern of mortality is more stable and the smoothed rates broadly feature improvements throughout.

\section{Figure 1a Annual percentage change in male smoothed mortality rates, England and Wales, 1913 to 2008 (three year rolling averages)}

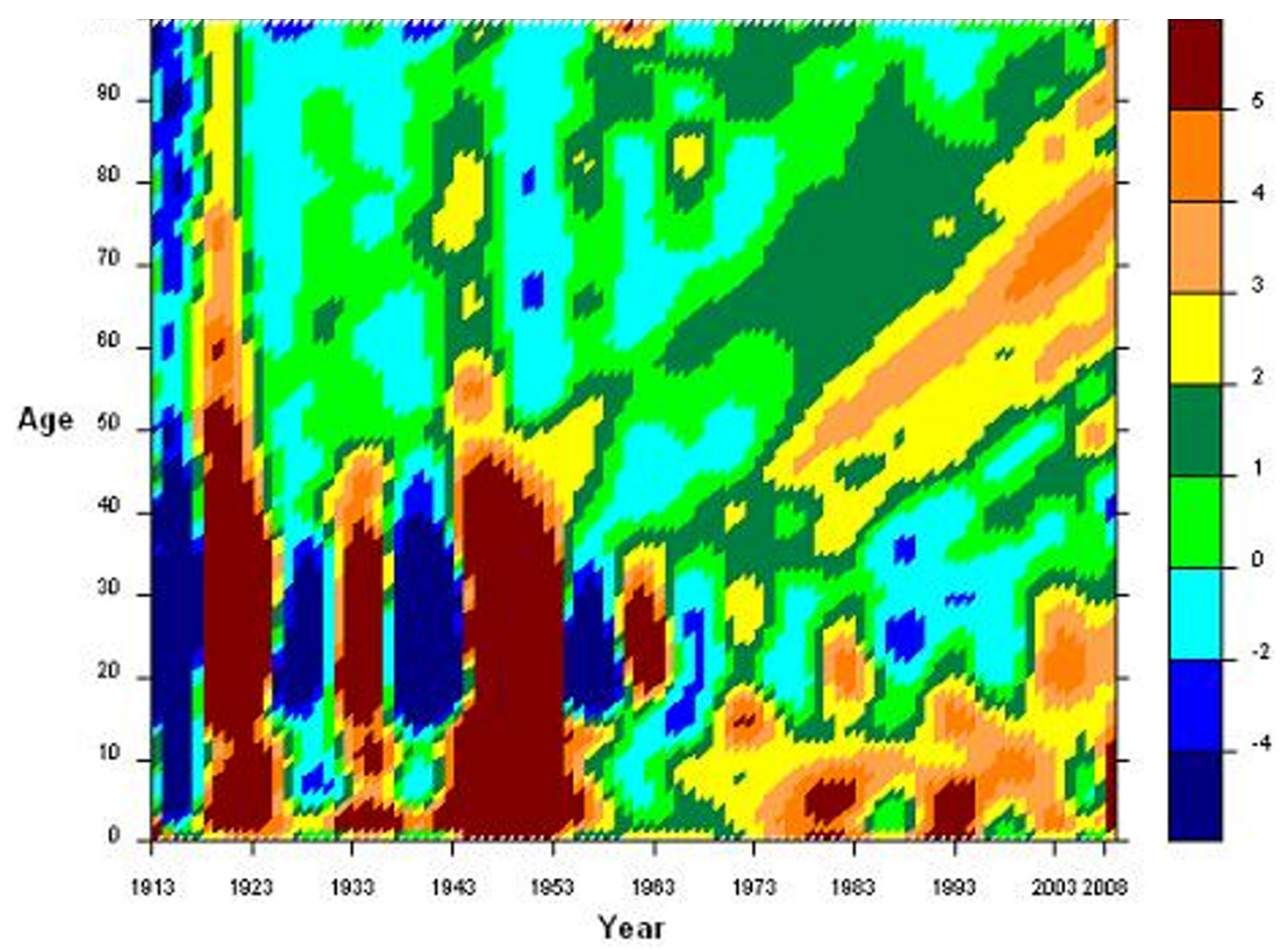

Source: Human Mortality Database; Office for National Statistics.

A distinct feature of the mortality improvements shown is the rapid improvement experienced by the cohort born between 1925 and 1934 from the mid-1970s onward (which we term cohort 2). It 
can be seen that this cohort has experienced greater mortality improvement than the cohorts born before (those born 1915-1924, which we term cohort 1) and after (those born 1935-1944, which we term cohort 3 ). These rapid improvements have followed them into increasingly older ages so that by 2008 , men and women aged between 73 and 81 experienced annual mortality improvements of at least three per cent.

\section{Figure $1 \mathrm{~b} \quad$ Annual percentage change in female smoothed mortality rates, England and Wales, 1913 to 2008 (three year rolling averages)}

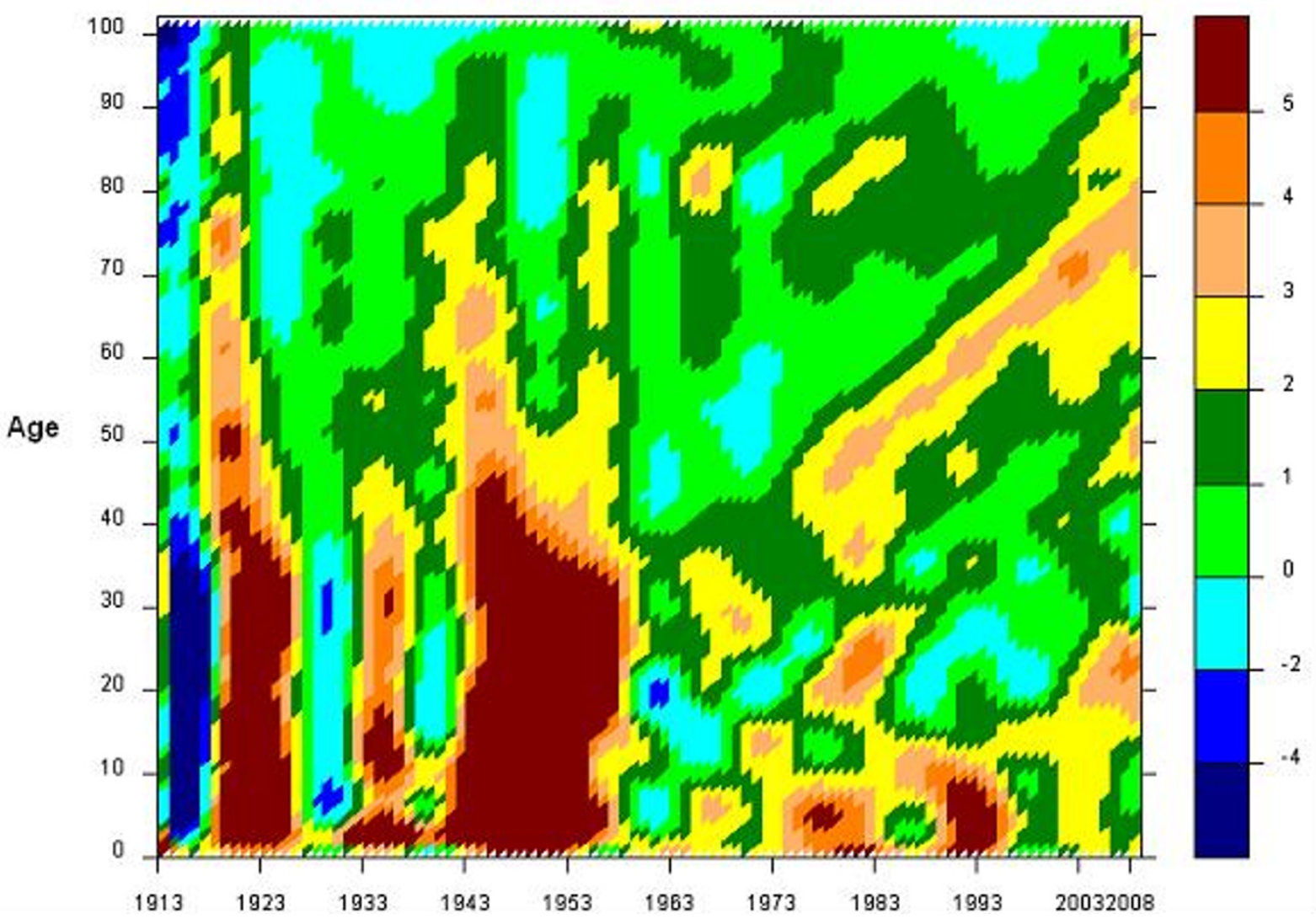

Source: Human Mortality Database; Office for National Statistics.

The cohort born between 1925 and 1934 also experienced rapid improvements in infant and child mortality. This may be explained by improvements in hygiene and nutrition along with the introduction of childhood immunisation for diseases such as diphtheria and tetanus. Following this period, those aged between about 16 and 40 experienced a rapid and prolonged reversal in the trend of improving mortality, brought about by the Second World War (1939-1945). However, the majority of the 1925-34 cohort experienced little change or even a slight improvement in mortality during this time. After the war, this cohort (along with all those born after 1890) began to experience a sustained period of mortality improvement in excess of three per cent annually. Rapid mortality improvements for this cohort persisted until 1953 when, for men aged around 18 to 30 , a brief but sharp reversal occurred. 


\section{Box 1 Calculating mortality rates}

\section{ONS mortality rate}

Age-specific mortality rate $=\frac{\text { deaths in age } / \text { sex group }}{\text { mid-year population in age } / \text { sex group }} \times 100,000$

Age-standardised mortality rates/ratios:

Age-standardised rates make allowances for differences in the age structure of the population, over time, between sexes and across areas. ONS LS and ONS mortality rates are standardised to the UK 2001 Standard Population.

\section{ONS LS mortality rate}

Age-specific mortality rate $=\frac{\text { deaths in age } / \text { sex group }}{\text { person-years of exposure in age } / \text { sex group }} \times 100,000$

The ONS LS mortality rates use person-years of exposure as the base population. This is the most accurate measure of the population at risk.

This lexis diagram provides an example of how the ONS LS mortality rates are calculated.

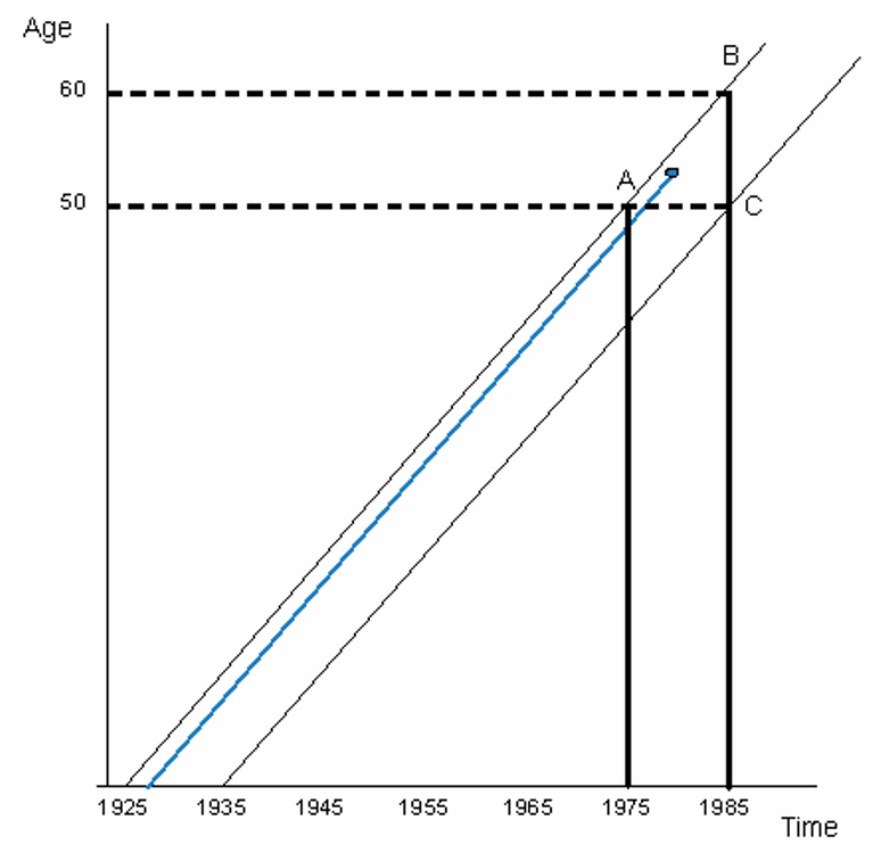

Fictitious Fred was born in 1927; he is one of the 1925 to 1934 birth cohort shown by the two parallel diagonal lines. We can follow Fred's life events by his life line, represented by the blue line on the diagram. Fred dies aged 53 in 1980. Fred's death will contribute to the numerator deaths to men aged 50 to 59 in the period 1975 to 1984 . The other deaths that will contribute to this rate will be represented by triangle $A B C$. This triangle represents all people from the 1925 to 1934 cohort that lived to at least 50; some of them will have continued to live on past 60 and their death record will be captured later; some of them will have died before the age of 60 . The person-years at risk are equal to the sum of all of the whole and part years every person in the 1925-34 cohort is alive and at risk of dying between 1975 and 1984. 
The 'golden cohort' may just have been born at the right time to benefit optimally from the health related improvements stated above and also avoid some of the more negative influences on mortality in the first half of the twentieth century. Figure 2 shows a timeline of significant events occurring between 1915 and 1965.

\section{Figure 2 Timeline of significant events during the period 1915-1965}

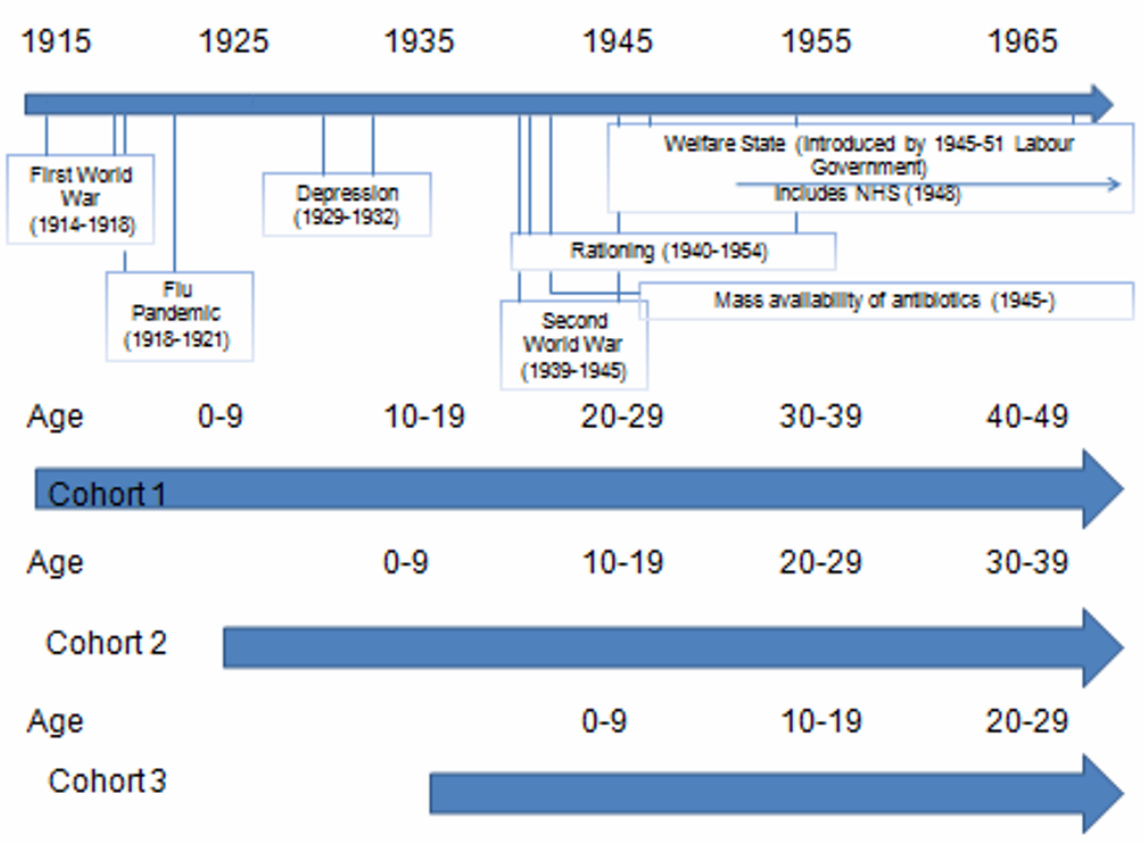

It is possible to see from the timeline that the cohort born in the decade preceding the 'golden cohort' would have been affected by the environmental conditions of the First World War and the Depression; many would have died from causes that did not affect later cohorts to the same degree. These men would also be called upon to fight in the Second World War. The 'golden cohort' would have experienced rationing during childhood and into early adulthood; this may have had a positive effect on their longer term health. Differences in smoking prevalence are likely to have had an influence on mortality improvements of the cohorts. Between 1890 and 1950 cigarettes largely replaced other tobacco products; in the early 20th century men were the main users of tobacco. Use by women commenced in the mid-1920s and, with few exceptions, was limited to cigarettes. Cigarette consumption increased rapidly in the Second World War and continued to increase until the 1970s, when it began to fall as a result of increased awareness of detrimental health effects ${ }^{6}$.

Cohort effects similar to that of the 'golden cohort' in England and Wales have been observed in France, Austria, Germany, Italy, Japan, Netherlands and Switzerland ${ }^{7}$. The effects for Italy, France and Germany are centred on the cohort born in the decade 1930 to 1940. It has been suggested that unfavourable conditions during the first years of life such as malnutrition and poor hygiene are a handicap to future survival. Caselli and Capocaccia (1989) investigated this hypothesis for Italy to determine whether cohorts with higher mortality at younger ages also had higher mortality 
throughout later life ${ }^{8}$. They found that cohorts growing up in unfavourable conditions caused by period effects such as war had higher mortality than other cohorts up to age 45 .

\section{Data sources}

Data from death registrations (referred to throughout as ONS deaths) and the Office for National Statistics Longitudinal Study (ONS LS) have been used in this study of mortality. ONS deaths data are based on the details collected when deaths are certified and registered. Deaths occurring within England and Wales to those resident outside England and Wales are included, whilst deaths to residents of England \& Wales occurring outside England and Wales are excluded.

The ONS LS contains linked census and vital event data for one per cent of the population of England and Wales. Information from the 1971, 1981, 1991 and 2001 Censuses has been linked across censuses as well as information on events such as births, deaths and cancer registrations. The original ONS LS sample included 1971 Census information for people born on one of four selected dates in a calendar year. These four dates were used to update the sample at the 1981 , 1991 and 2001 Censuses and to add new members between censuses. The ONS LS is a dynamic sample with new members being constantly added through births and immigrations. Box 2 shows the information held in the ONS LS.

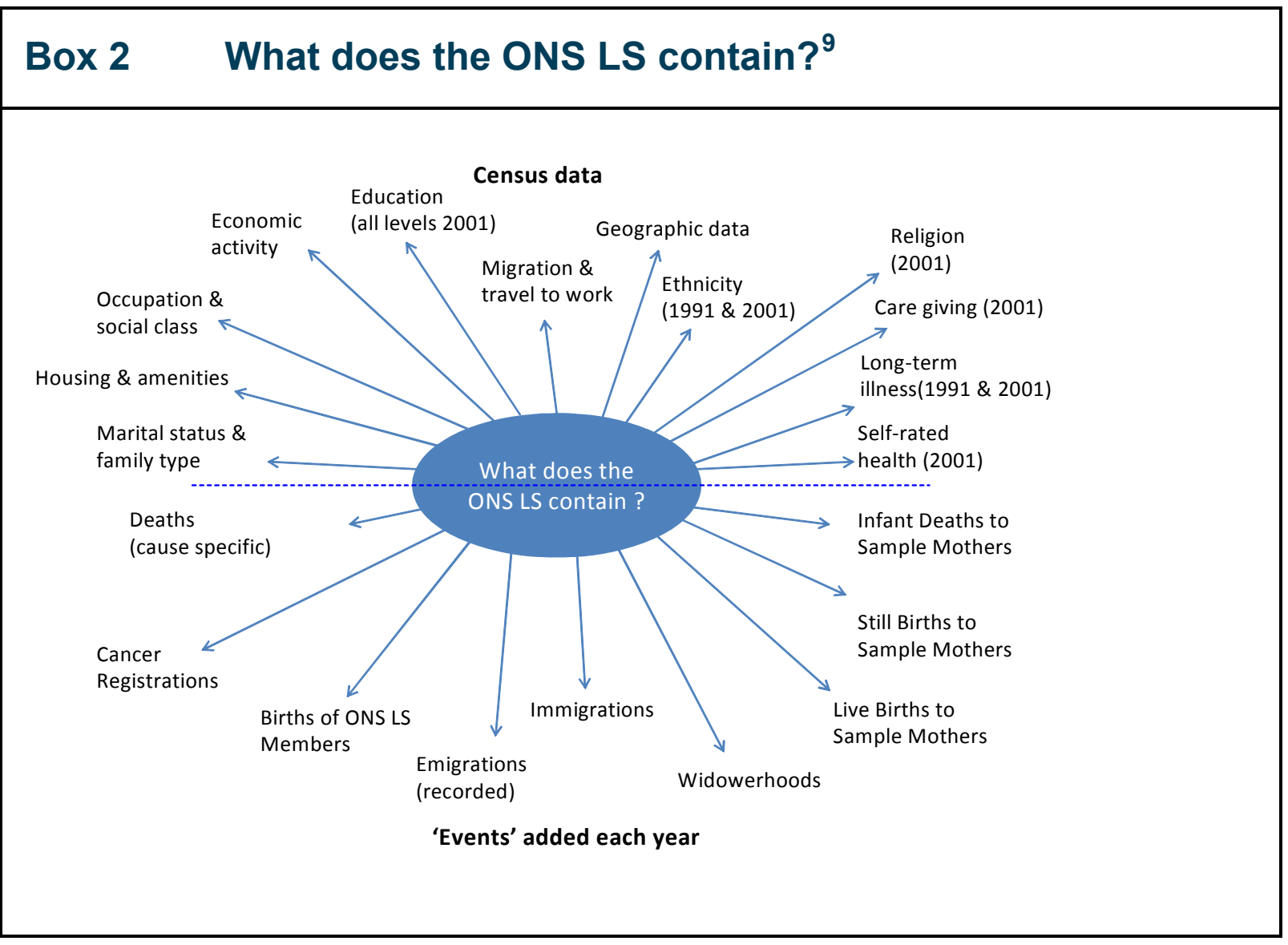

Data on approximately one million sample members have been collected over the 40 years of the study. At each census, data on slightly more than 500,000 sample members are collected. Those included in the one per cent sample are referred to as 'ONS LS members'. 
The ONS LS is appropriate for this study as it is the only data set which contains linked individual level data on mortality with individual level census data and vital events information in England and Wales. One of the reasons the ONS LS was set up was to enable prospective analysis of census and event data, including the analysis of the effects of employment status on mortality. In addition, the census coverage rates and the linkage and trace rates (see Box 3) obtained in the ONS LS compare very favourably with response rates achieved in surveys.

\section{Box 3 Explaining matching, tracing and linking in the ONS LS $^{10}$}

Tracing, matching and linkage are key issues to be considered when defining a study population.

Tracing is the process of finding an ONS LS member's record in the NHS Central Register (NHSCR). Once a person has been traced, we can study the events that they experience.

After a new set of census records is added to the ONS LS, there will be a number of ONS LS members who were present at the previous census but are no longer present in the new census. Most of these people will have either died or left England and Wales ('embarked') in the inter-censal period. However, there will be a remnant whose absence is unexplained. These include people who have misreported their date of birth or who have not been enumerated in the census. There will also be a number of unmatched records in the new intake that should have entered the ONS LS via immigration or birth registration. Such records highlight deficiencies in these registrations or deficient information on the census form, for example, an ONS LS member writes down the wrong date of birth. These cases are linkage failures (see below).

Matching consists of taking a census record for a person born on an ONS LS date of birth, and finding a corresponding record for that person in the ONS LS. If a record has been successfully matched, we can study that person longitudinally.

Linking is the term used to describe the process of checking whether an ONS LS member present at one census is present at the one before (backwards linkage) or the one after (forwards linkage). For example, Fred is present at the 1981 Census, no events are added in the inter-censal period, however, he fails to turn up at the 1991 Census. This is a forward linkage failure.

The quality of linkage is measured by the linkage rate. For a given group (for example everyone present at a given census, or all new births during one inter-censal period), the linkage rate to the following census is given by the proportion of members of that group who are successfully matched at the next census.

Linkage rates for the ONS LS are high overall (over 90 per cent between successive censuses), but are lower for certain subgroups.

This study is based on analysis of the three birth cohorts 1915-1924, 1925-1934, and 1935-1944. These are designed to represent approximately the 'golden cohort' and the cohorts either side. By 
comparing ONS LS members born in this cohort with the cohorts either side we can explore any significant differences in their mortality experiences and social and demographic characteristics.

The data extract used for the analysis to compare ONS LS death rates with the ONS death rates based on death registration data contains all people who were present and traced at the 1971 Census and who did not die before 1 January 1972. A total of 219,866 ONS LS members are included in this extract. This extract is the most comparable with the ONS death registration data, which includes deaths occurring within England and Wales for usual residents and non-residents. Figure 3 shows the ageing of the ONS LS members in the data extract we have taken over the follow-up period. The extract includes deaths information up to and including 2009.

\section{Figure 3 Cohorts represented in the ONS LS data extract}

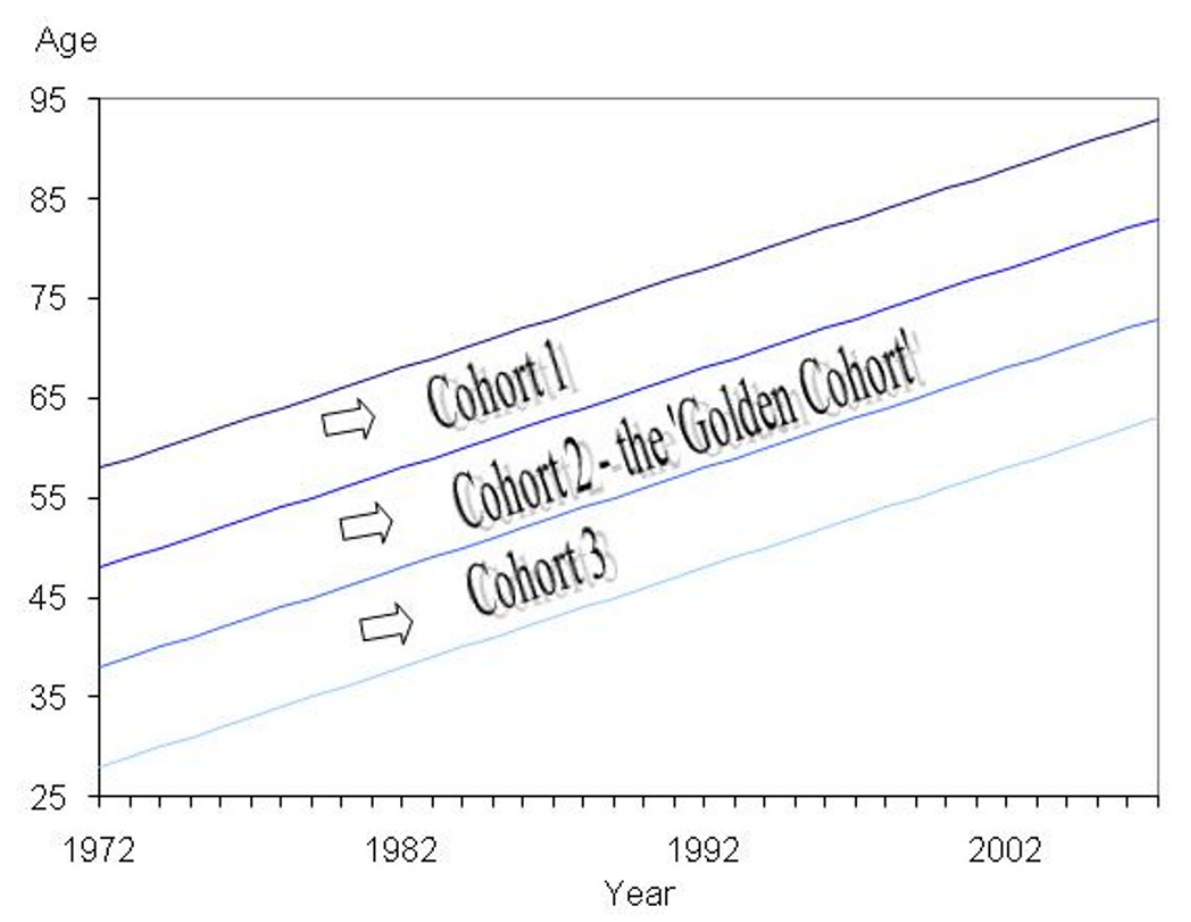

The extract was then used to create three comparable datasets, one for each cohort. For the purposes of analysis, certain exclusions were applied to the ONS LS sample:

- Those who could not be traced at the NHS Central Register ${ }^{11}$ were excluded since their deaths will not be linked to their ONS LS records

- Those who were recorded as emigrating were included up to the point of their emigration but excluded subsequently, even if there was a subsequent record of re-entry. This is because there is a danger of bias in including their records in the denominators of mortality rates; they may not be 'at risk' for the purpose of this analysis if they are not actually domiciled in England and Wales and their deaths will almost certainly not be linked to their ONS LS record ${ }^{12}$

- All members who were not known to have died, emigrated or enlisted in the armed forces but were not found at census were excluded, as were immigrants who were not present at any census

- Those who were not born in England and Wales were excluded. Murphy (2009) stated that using data with both England and Wales and non England and Wales born to observe 
differences in cohort mortality in England and Wales can be potentially misleading if there is a difference in mortality by country of birth

- Those who died within five years of the census at the start of their follow up decade were removed to leave a 'wear-off' period. Analysing mortality by economic position and social class is complicated because failing health may increase the probability of unemployment ${ }^{13}$. Leaving a 'wear-off' period between the observation of economic position/social class removes any health selection effects

The sample sizes of the data sets are shown in Table 2.

\section{Table 2 ONS LS sample size details, by birth cohort}

\begin{tabular}{crrr}
\hline & Cohort 1 & Cohort 2 & Cohort 3 \\
& $\mathbf{1 9 1 5 - 2 4}$ & $\mathbf{1 9 2 5 - 3 4}$ & $\mathbf{1 9 3 5 - 4 4}$ \\
\hline Total ONS LS sample members & 66,729 & 75,198 & 82,728 \\
less those untraced on NHSCR & 65,625 & 73,605 & 80,636 \\
less members born outside England and Wales & 51,994 & 52,233 & 53,296 \\
less members who are not present at census & 51,378 & 51,611 & 52,620 \\
less members who died within five years of census & 49,116 & 49,613 & 50,121 \\
Total sample for analysis & 49,116 & 49,613 & 50,121 \\
\hline
\end{tabular}

The socio-economic analyses in this article are based on the ONS LS samples of men and women who survived to the beginning of years 1977, 1987 and 1997 for cohorts 1, 2 and 3 respectively. However, the socio-economic information provided by the census always relates to the census prior to the year in question unless otherwise stated.

It was necessary to carry out some recoding of the census socio-economic variables used for analysis purposes to ensure consistency over time. The following variables were used to analyse whether there were any underlying differences in the cohorts and their mortality: tenure, social class, education level, marital status and economic position. These variables are all known to be factors linked with mortality differentials ${ }^{13,14,15,16,17,18,19}$.

\section{Analytical approach}

\section{Comparing data sources}

The ONS LS has been used to calculate standardised aggregated mortality rates. This section compares the ONS LS and ONS mortality rates for quality assessment purposes.

Calculating a basic mortality rate is explained in Box 1. Each mortality rate shown in this article relates to a birth cohort, age group and year of analysis. In addition the rates calculated are based on three years of data and are standardised. Box 4 explains the mortality rate calculations in more detail. 


\section{Box $4 \quad$ Calculating ONS LS Mortality rates}

\section{Calculating the ONS LS sample mortality rates}

The ONS LS mortality rate for men aged 55-59 born in cohort 2, for the three year period centred on 1988, is calculated as follows:

Firstly, we calculate the ONS LS sample mortality rates, sample $m_{x}$ (shown as equation 1), by single year of age (x), using data from 1987, 1988 and 1989. These are equal to the deaths in each age/sex group ( sample $d_{x}$ ) in the sample, divided by the person-years exposed $\left({ }^{\text {sample }} p_{x}\right)$ in each age/sex group in the sample. The data used in this calculation is shown in the diagram below as the blue shaded area.

\begin{tabular}{|c|c|c|c|c|c|c|c|c|c|c|c|}
\hline & 1989 & 64 & 63 & 62 & 61 & 60 & 59 & 58 & 57 & 56 & 55 \\
\hline of & 1988 & 63 & 62 & 61 & 60 & 59 & 58 & 57 & 56 & 55 & 54 \\
\hline analysis & 1987 & 62 & 61 & 60 & 59 & 58 & 57 & 56 & 55 & 54 & 53 \\
\hline & & $\begin{array}{c}1925 \\
\text { Birth }\end{array}$ & 1926 & 1927 & 1928 & 1929 & 1930 & 1931 & 1932 & 1933 & 1934 \\
\hline
\end{tabular}

The next stage of the calculation is age standardisation (shown as equation 2). The ONS LS sample mortality rates by single year of age are multiplied by the 2001 standard UK population by single year of age and summed for all ages $55-59$. This gives the standardised number of deaths for men aged 55-59. This figure is then divided by the standard population aged 55-59, to give a standardised rate, and then multiplied by 100,000 to give a rate per 100,000 .

1)

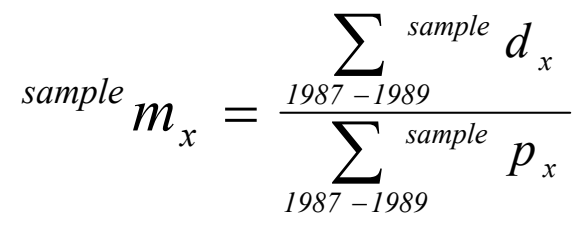

2) ${ }_{\text {standardised }} m_{55-59}=\frac{\sum_{\text {Age } 55-59}\left({ }^{\text {sample }} m_{x} \times{ }^{\text {standardised }} P_{x}\right)}{\sum_{\text {Age } 55-59}{ }^{\text {standardised }} P_{x}} \times 100,000$

Figures $4 \mathrm{a}$ and $\mathbf{4 b}$ show that the mortality rates calculated using the ONS LS are consistent with the ONS mortality rates. Both sources show that mortality rates are generally improving over time for each age group. Table 3 shows the differences between the ONS LS and ONS mortality rates are generally small in percentage terms. 
Figure 4a Comparisons of ONS LS standardised aggregated mortality rates with ONS standardised aggregated mortality rates based on death registrations, men, England and Wales

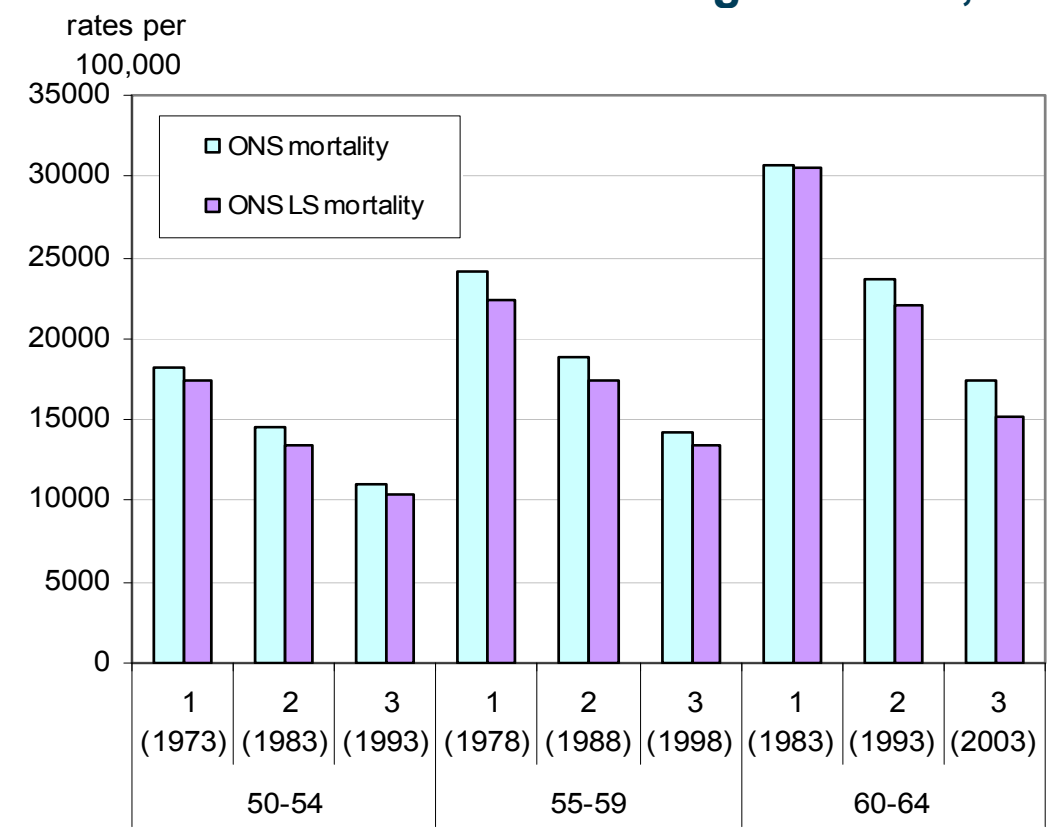

Note: the numbers on the x-axis refer to the cohort; the year in brackets refers to the reference year which is the centre year of the three years of data that are aggregated to produce the mortality rates; the age bands refer to the age at death.

Source: Office for National Statistics

Figure 4b Comparisons of ONS LS standardised aggregated mortality rates with ONS standardised aggregated mortality rates based on death registrations, women, England and Wales

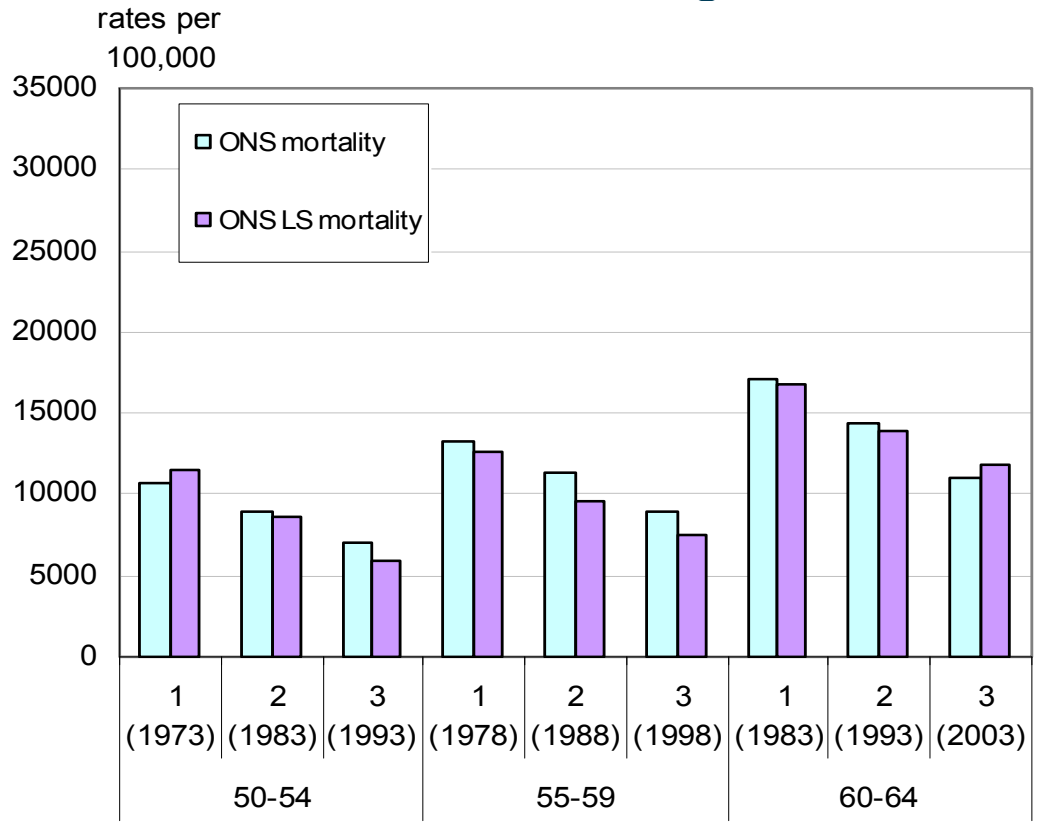

Note: the numbers on the x-axis refer to the cohort; the year in brackets refers to the reference year which is the centre year of the three years of data that are aggregated to produce the mortality rates; the age bands refer to the age at death.

Source: Office for National Statistics 


\section{Table $3 \quad$ ONS and ONS LS standardised aggregated mortality rates by age group, cohort and sex, England and Wales}

\begin{tabular}{|c|c|c|c|c|c|c|c|}
\hline \multirow[b]{2}{*}{ Age } & \multirow{2}{*}{$\begin{array}{l}\text { Birth cohort } \\
\text { (year) }\end{array}$} & \multicolumn{2}{|c|}{ ONS LS Mortality } & \multicolumn{2}{|c|}{ ONS Mortality } & \multicolumn{2}{|c|}{$\begin{array}{l}\text { Relative difference } \\
(\%) \text { ONS LS and } \\
\text { ONS mortality rates }\end{array}$} \\
\hline & & Men & Women & Men & Women & Males & Females \\
\hline \multirow[t]{3}{*}{$50-54$} & $1(1973)$ & 17,418 & 11,535 & 18,197 & 10,743 & -4 & 7 \\
\hline & $2(1983)$ & 13,380 & 8,596 & 14,546 & 9,020 & -8 & -5 \\
\hline & $3(1993)$ & 10,372 & 5,990 & 11,056 & 7,076 & -6 & -15 \\
\hline \multirow[t]{3}{*}{$55-59$} & $1(1978)$ & 22,385 & 12,649 & 24,161 & 13,280 & -7 & -5 \\
\hline & $2(1988)$ & 17,487 & 9,554 & 18,862 & 11,283 & -7 & -15 \\
\hline & $3(1998)$ & 13,427 & 7,508 & 14,284 & 8,886 & -6 & -16 \\
\hline \multirow[t]{3}{*}{$60-64$} & $1(1983)$ & 30,479 & 16,779 & 30,683 & 17,145 & -1 & -2 \\
\hline & $2(1993)$ & 22,043 & 13,838 & 23,653 & 14,409 & -7 & -4 \\
\hline & $3(2003)$ & 15,112 & 11,814 & 17,364 & 11,037 & -13 & 7 \\
\hline
\end{tabular}

Notes: Negative relative differences: ONS LS mortality rates are lower than ONS mortality rates.

The numbers on the x-axis refer to the cohort; the year in brackets refers to the reference year which is the centre year of the three years of data that are aggregated to produce the mortality rates; the age bands refer to the age at death.

Source: Office for National Statistics

Table 4 shows the actual change in ONS LS mortality rates. It can be seen that the mortality improvement between cohorts 1 and 2 is consistently numerically greater than between cohorts 2 and 3 for both males and females. However when percentage changes are examined this is less clear, but that is also true for the ONS mortality rates.

Table $4 \quad$ Change in ONS LS mortality rates by age group, cohort and sex, England and Wales

\begin{tabular}{|c|c|c|c|c|c|}
\hline \multirow[t]{2}{*}{ Age } & \multirow[t]{2}{*}{ Cohort (Year) } & \multicolumn{4}{|c|}{ Decrease in mortality rate (per 100,000 ) } \\
\hline & & \multicolumn{2}{|c|}{ Males } & \multicolumn{2}{|c|}{ Females } \\
\hline \multirow{4}{*}{$50-54$} & & Number & Percentage & Number & Percentage \\
\hline & $1(1973)$ & & & & \\
\hline & $2(1983)$ & -4038 & $-23 \%$ & -2939 & $-25 \%$ \\
\hline & $3(1993)$ & -3007 & $-22 \%$ & -2606 & $-30 \%$ \\
\hline \multirow[t]{3}{*}{$55-59$} & $1(1978)$ & & & & \\
\hline & $2(1988)$ & -4899 & $-22 \%$ & -3095 & $-24 \%$ \\
\hline & $3(1998)$ & -4060 & $-23 \%$ & -2046 & $-21 \%$ \\
\hline \multirow[t]{3}{*}{$60-64$} & $1(1983)$ & & & & \\
\hline & $2(1993)$ & -8435 & $-28 \%$ & -2941 & $-18 \%$ \\
\hline & $3(2003)$ & -6931 & $-31 \%$ & -2024 & $-15 \%$ \\
\hline
\end{tabular}

Note: the numbers on the x-axis refer to the cohort; the year in brackets refers to the reference year which is the centre year of the three years of data that are aggregated to produce the mortality rates; the age bands refer to the age at death.

Source: Office for National Statistics

\section{Analysis of the LS data by social and demographic characteristics}

The overall change in mortality will be the result of both changes in mortality by demographic characteristics and changes in composition of the population by demographic characteristic. In order to narrow down the research the remaining analysis concentrates on the middle age group in 
Table 4, mortality at age 55-59. The socio-economic analyses in this article are based on the ONS LS samples of men and women who survived to the beginning of years 1977, 1987 and 1997 for cohorts 1, 2 and 3 respectively. However, the socio-economic information provided by the census always relates to the census prior to the year in question unless otherwise stated. The mortality rates by socio-economic status are based on three years of data centred on 1978, 1988 and 1998 for cohorts 1, 2 and 3 respectively.

The ONS LS data has been used to compare the composition and mortality rates for each cohort in terms of its sex, tenure, social class, marital status, education and economic position. The aim is to examine whether differences in the underlying population and mortality rates by characteristic in each cohort are driving the improvements seen. The following section describes each of the characteristics examined. It shows the initial population structure and also the standardised mortality rates calculated. After this descriptive section an attempt to quantify the effects of population composition and mortality change on overall mortality improvement is presented.

\section{Marital status}

Tables $\mathbf{5 a}$ and $\mathbf{5 b}$ show a slight general downward trend in the percentage married with each successive cohort and an upward trend in the percentage divorced. Both the health selection and

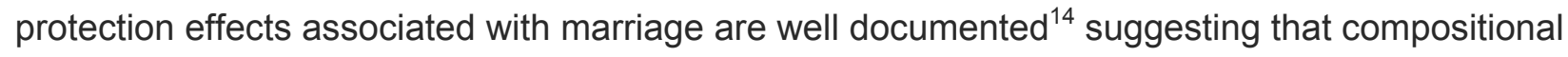
change would, other things being equal, dampen any mortality decrease. Therefore, the overall fall in mortality is likely to relate to changes in the mortality in the specific states. The analysis of standardised aggregated mortality rates by marital status (Figures $\mathbf{5 a}$ and $\mathbf{5 b}$ ) show a decline in mortality across the cohorts for those who are married and those who are divorced, although mortality rates for both divorced men and women are consistently higher than those for married men and women.

\section{Table 5a Percentage distribution of ONS LS sample members by marital status, men aged 55-59}

\begin{tabular}{|c|c|c|c|c|c|c|c|c|c|}
\hline \multirow[b]{2}{*}{ Cohort } & \multicolumn{2}{|c|}{ Single } & \multicolumn{2}{|c|}{ Married } & \multicolumn{2}{|c|}{ Widowed } & \multicolumn{2}{|c|}{ Divorced } & \multirow[b]{2}{*}{ Total (Number) } \\
\hline & Percentage & $\begin{array}{r}\text { rcentage } \\
\text { point } \\
\text { change }\end{array}$ & Percentage & $\begin{array}{r}\text { Percentage } \\
\text { point } \\
\text { change } \\
\end{array}$ & Percentage & $\begin{array}{r}\text { Percentage } \\
\text { point } \\
\text { change } \\
\end{array}$ & Percentage & $\begin{array}{r}\text { Percentage } \\
\text { point } \\
\text { change } \\
\end{array}$ & \\
\hline 1 & 9 & .. & 88 & .. & 2 & .. & 2 & .. & $100(23,371)$ \\
\hline 2 & 9 & 0 & 85 & -3 & 2 & 0 & 4 & 2 & $100(24,365)$ \\
\hline 3 & 8 & -1 & 82 & -3 & 1 & -1 & 8 & 4 & $100(24,878)$ \\
\hline
\end{tabular}

Source: Office for National Statistics

\section{Table $5 \mathrm{~b} \quad$ Percentage distribution of ONS LS sample members by} marital status, women aged $55-59$

\begin{tabular}{|c|c|c|c|c|c|c|c|c|c|}
\hline \multirow[b]{2}{*}{ Cohort } & \multicolumn{2}{|c|}{ Single } & \multicolumn{2}{|c|}{ Married } & \multicolumn{2}{|c|}{ Widowed } & \multicolumn{2}{|c|}{ Divorced } & \multirow[b]{2}{*}{ Total (Number) } \\
\hline & Percentage & $\begin{array}{r}\text { Percentage } \\
\text { point } \\
\text { change } \\
\end{array}$ & Percentage & $\begin{array}{r}\text { Percentage } \\
\text { point } \\
\text { change } \\
\end{array}$ & Percentage & $\begin{array}{r}\text { Percentage } \\
\text { point } \\
\text { change } \\
\end{array}$ & Percentage & $\begin{array}{r}\text { Percentage } \\
\text { point } \\
\text { change } \\
\end{array}$ & \\
\hline 1 & 8 & .. & 84 &.. & 6 & .. & 2 & .. & $100(25,745)$ \\
\hline 2 & 6 & -2 & 83 & -1 & 6 & -0 & 5 & 3 & $100(25,248)$ \\
\hline 3 & 5 & -1 & 80 & -3 & 5 & -1 & 11 & 6 & $100(25,243)$ \\
\hline
\end{tabular}

Source: Office for National Statistics 


\section{Figure 5a ONS LS standardised aggregated mortality rates by marital status, men aged 55-59}

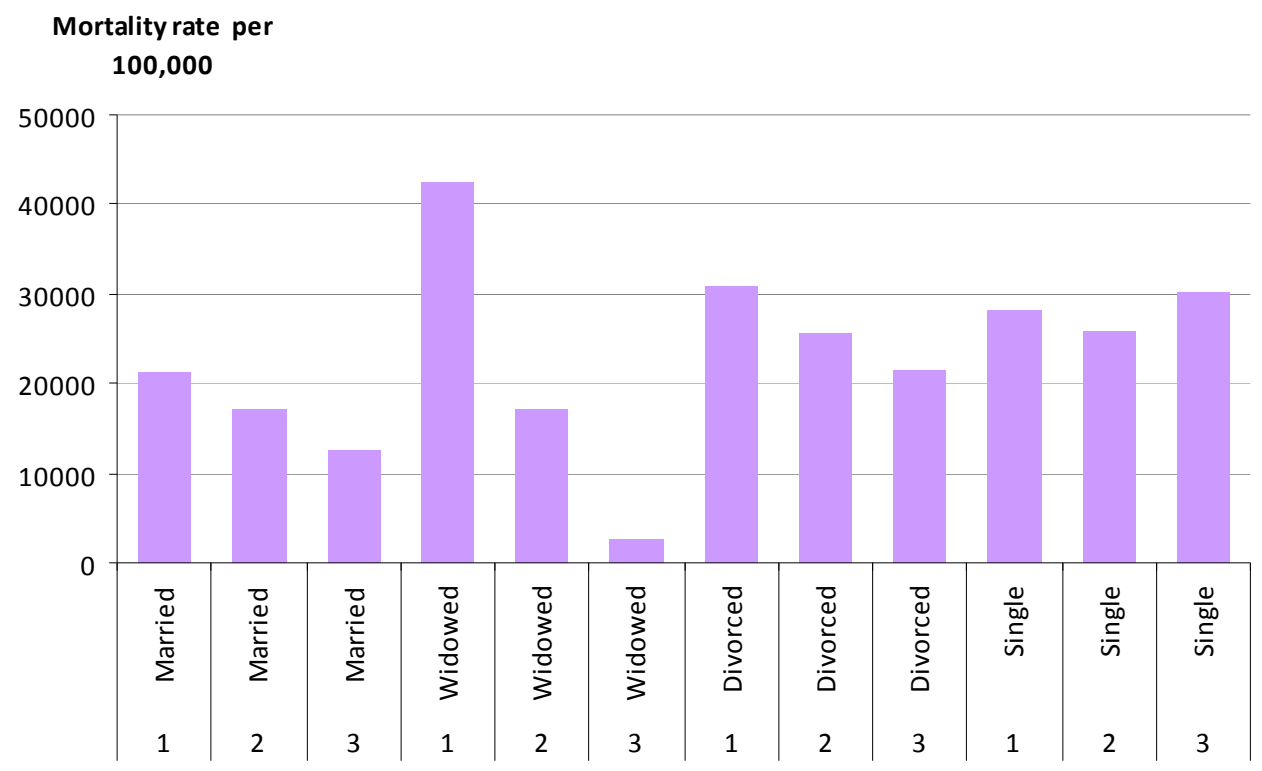

Note: Minimum sample size: 219 men aged 55-59 at risk of dying.

Source: Office for National Statistics

Figure 5b ONS LS standardised aggregated mortality rates by marital status, women aged $55-59$

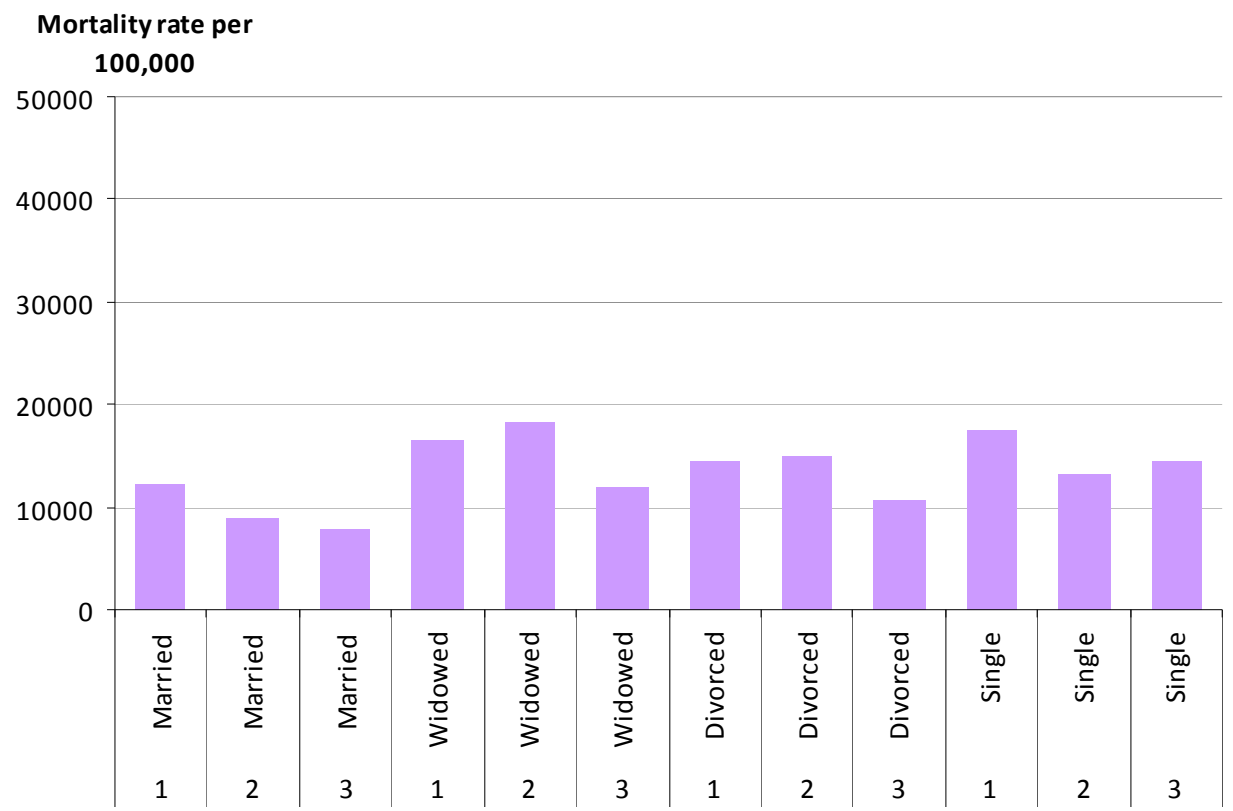

Note: Minimum sample size: 495 women aged 55-59 at risk of dying.

Source: Office for National Statistics 


\section{Economic position}

Tables $6 \mathbf{a}$ and $\mathbf{6 b}$ show that the percentage of men in employment declined with each successive decade. The percentage of men aged 55-59 who were unemployed rose between cohort 1 and cohort 2 but then declined slightly in cohort 3 . The percentage of women in employment increased with each decade whilst unemployment remained relatively stable. These decades have seen increasing numbers of women joining the workforce in a variety of employment sectors, helped by the general move from heavy industry to service activity in the last three decades of the twentieth century ${ }^{15}$. Both the number and percentage of permanently sick men and women have increased over each cohort. The increases seen between cohort 2 and cohort 3 are nearly three times greater for men and six times greater for women when compared with those seen between cohort 1 and cohort 2 . The increase in the number described as permanently sick may reflect changes in health perception but may also reflect the decline of traditional industries such as mining and textiles in the 1980s which contributed to rising unemployment and deprivation in the older industrial regions ${ }^{16}$.

Table 6a Percentage distribution of ONS LS sample members by economic position, men aged 55-59

\begin{tabular}{|c|c|c|c|c|c|c|c|c|c|}
\hline \multirow[t]{2}{*}{ Cohort } & \multicolumn{2}{|c|}{ Employed } & \multicolumn{2}{|c|}{ Unemployed } & \multicolumn{2}{|c|}{ Permanently sick } & \multicolumn{2}{|c|}{ Other } & \multirow{2}{*}{$\begin{array}{r}\text { Total } \\
\text { (number) }\end{array}$} \\
\hline & Percentage & $\begin{array}{r}\text { Percentage } \\
\text { point } \\
\text { change }\end{array}$ & Percentage & $\begin{array}{r}\text { Percentage } \\
\text { point } \\
\text { change }\end{array}$ & Percentage & $\begin{array}{r}\text { Percentage } \\
\text { point } \\
\text { change }\end{array}$ & Percentage & $\begin{array}{r}\text { Percentage } \\
\text { point } \\
\text { change }\end{array}$ & \\
\hline 1 & 95 & .. & 3 &.. & 1 & .. & 1 & .. & $100(23,371)$ \\
\hline 2 & 89 & -6 & 7 & 4 & 3 & 2 & 1 & 0 & $100(24,365)$ \\
\hline 3 & 85 & -4 & 6 & 1 & 7 & 4 & 2 & 1 & $100(24,878)$ \\
\hline
\end{tabular}

Source: Office for National Statistics

\section{Table $6 \mathrm{~b} \quad$ Percentage distribution of ONS LS sample members by economic position, women aged $55-59$}

\begin{tabular}{|c|c|c|c|c|c|c|c|c|c|}
\hline \multirow[t]{2}{*}{ Cohort } & \multicolumn{2}{|c|}{ Employed } & \multicolumn{2}{|c|}{ Unemployed } & \multicolumn{2}{|c|}{ Permanently sick } & \multicolumn{2}{|c|}{ Other } & \multirow{2}{*}{$\begin{array}{r}\text { Total } \\
\text { (number) }\end{array}$} \\
\hline & $\begin{array}{l}\text { Percentage } \\
\text {. }\end{array}$ & $\begin{array}{r}\text { Percentage } \\
\text { point } \\
\text { change }\end{array}$ & Percentage & $\begin{array}{r}\text { Percentage } \\
\text { point } \\
\text { change }\end{array}$ & Percentage & $\begin{array}{r}\text { Percentage } \\
\text { point } \\
\text { change }\end{array}$ & Percentage & $\begin{array}{r}\text { Percentage } \\
\text { point } \\
\text { change }\end{array}$ & \\
\hline 1 & 58 & .. & 2 & .. & 1 &.. & 39 & .. & $100(25,745)$ \\
\hline 2 & 63 & 5 & 3 & 1 & 2 & 1 & 33 & -6 & $100(25,248)$ \\
\hline 3 & 67 & 4 & 3 & 0 & 6 & 4 & 24 & -9 & $100(25,243)$ \\
\hline
\end{tabular}

Source: Office for National Statistics

Figures $\mathbf{6 a}$ and $\mathbf{6 b}$ show mortality rates by economic position for each cohort by sex and economic position. The unemployed and permanently sick have higher mortality than both the employed and other groups for men and women in every decade. Also the mortality rate worsens for both permanently sick men and women between cohort 1 and cohort 2 . 
Figure $6 a$ ONS LS standardised aggregated mortality rates by economic position, men aged 55-59

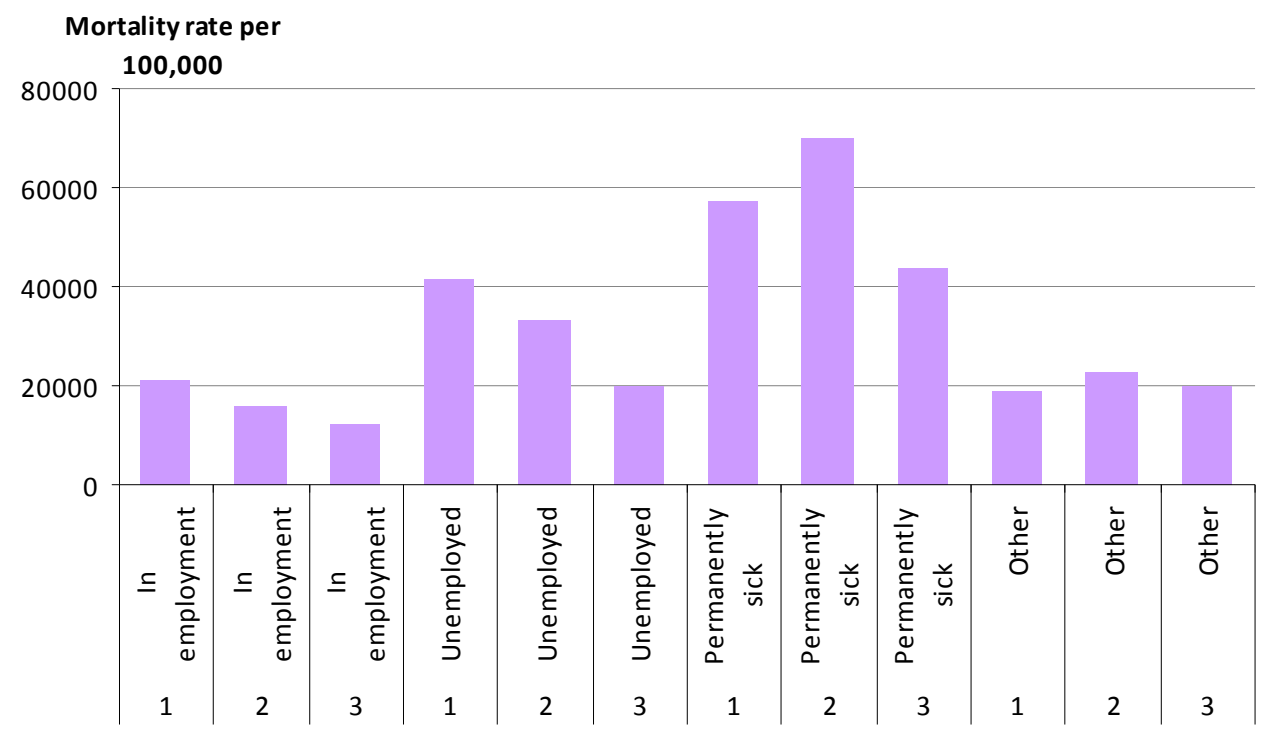

Note: Minimum sample size: 99 men aged 55-59 at risk of dying.

Source: Office for National Statistics

Figure $6 \mathrm{~b}$ ONS LS standardised aggregated mortality rates by economic position, women aged 55-59

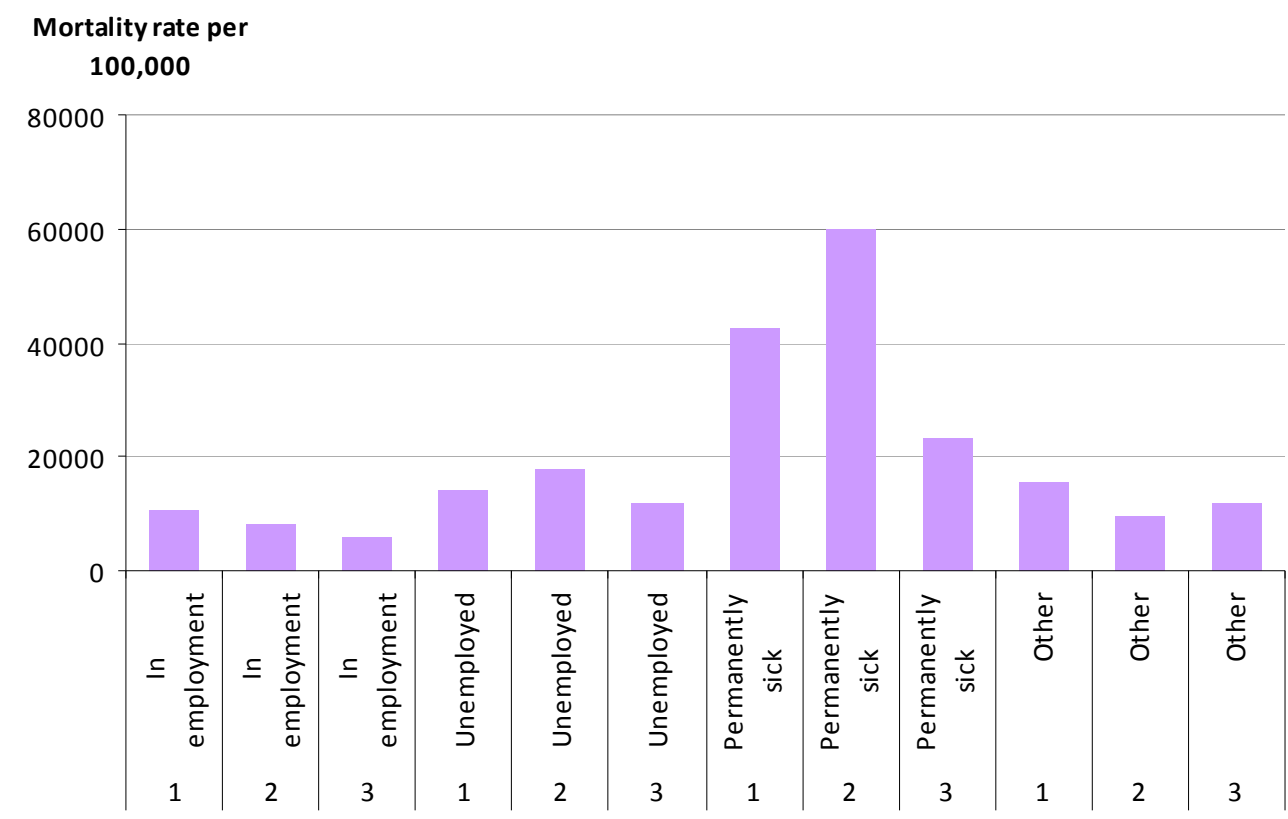

Minimum sample size: 274 women aged 55-59 at risk of dying.

Source: Office for National Statistics 


\section{Social class}

Tables $7 \mathbf{a}$ and $\mathbf{7 b}$ show the composition of the cohorts aged $55-59$, by sex and social class. In order to carry out the analysis some combining of the higher level social class categories has been carried out. The percentage in the 'professional and intermediate' group increased between cohort 1 and cohort 2 for men, but then stabilised, whereas for women the percentage increased across all three cohorts. There have been consistent declines in the percentage in the remaining groups with the exception of 'other' for men aged 55-59.

\section{Table $7 a \quad$ Percentage distribution of ONS LS members by social class, men aged $55-59$}

\begin{tabular}{rrrrrrrr}
\hline Cohort & $\begin{array}{r}\text { Professional/ } \\
\text { Intermediate } \\
\text { Skilled non-manual }\end{array}$ & $\begin{array}{r}\text { Percentage } \\
\text { point } \\
\text { change }\end{array}$ & $\begin{array}{r}\text { Skilled manual } \\
\text { Partly skilled } \\
\text { Unskilled }\end{array}$ & $\begin{array}{r}\text { Percentage } \\
\text { point } \\
\text { change }\end{array}$ & $\begin{array}{c}\text { Other* } \\
\text { Percentage } \\
\text { point } \\
\text { change }\end{array}$ & $\begin{array}{r}\text { Total (Number) } \\
\hline \mathbf{1}\end{array}$ \\
$\mathbf{2}$ & 46 &. & 61 &. & 3 &.. & $100(23,371)$ \\
$\mathbf{3}$ & 42 & 6 & 55 & -6 & 3 & 0 & $100(24,365)$ \\
\hline
\end{tabular}

Note: *'Other' includes those permanently sick, looking after family, those who are retired, in the armed forces and students.

Source: Office for National Statistics

\section{Table $7 \mathrm{~b} \quad$ Percentage distribution of ONS LS members by social class, women aged 55-59}

\begin{tabular}{rrrrrrrr}
\hline Cohort & $\begin{array}{r}\text { Professional/ } \\
\text { Intermediate } \\
\text { Skilled non-manual }\end{array}$ & $\begin{array}{r}\text { Percentage } \\
\text { point } \\
\text { change }\end{array}$ & $\begin{array}{r}\text { Skilled manual } \\
\text { Partly skilled } \\
\text { Unskilled }\end{array}$ & $\begin{array}{r}\text { Percentage } \\
\text { point } \\
\text { change }\end{array}$ & $\begin{array}{c}\text { Other* } \\
\text { Percentage } \\
\text { point } \\
\text { change }\end{array}$ & $\begin{array}{r}\text { Total (Number) } \\
\hline \mathbf{1}\end{array}$ \\
2 & 30 &. & 29 &.. & 42 &.. & $100(25,745)$ \\
$\mathbf{2}$ & 39 & 9 & 27 & -2 & 35 & -7 & $100(25,248)$ \\
$\mathbf{3}$ & 51 & 12 & 29 & 2 & 20 & -15 & $100(25,243)$ \\
\hline
\end{tabular}

Note: *'Other' includes those permanently sick, looking after family, those who are retired, in the armed forces and students.

Source: Office for National Statistics

Figures $\mathbf{7 a}$ and $\mathbf{7 b}$ show consistent mortality improvements for the 'Professional, intermediate and skilled non-manual' and 'Skilled, part skilled, unskilled' social classes for both men and women. The 'Professional, intermediate and skilled non-manual' class consistently has the lowest mortality across the cohorts for both males and females. This confirms findings from previous research using the ONS LS ${ }^{17}$. 


\section{Figure $7 a \quad$ ONS LS standardised aggregated mortality rates by social class, men aged 55-59}

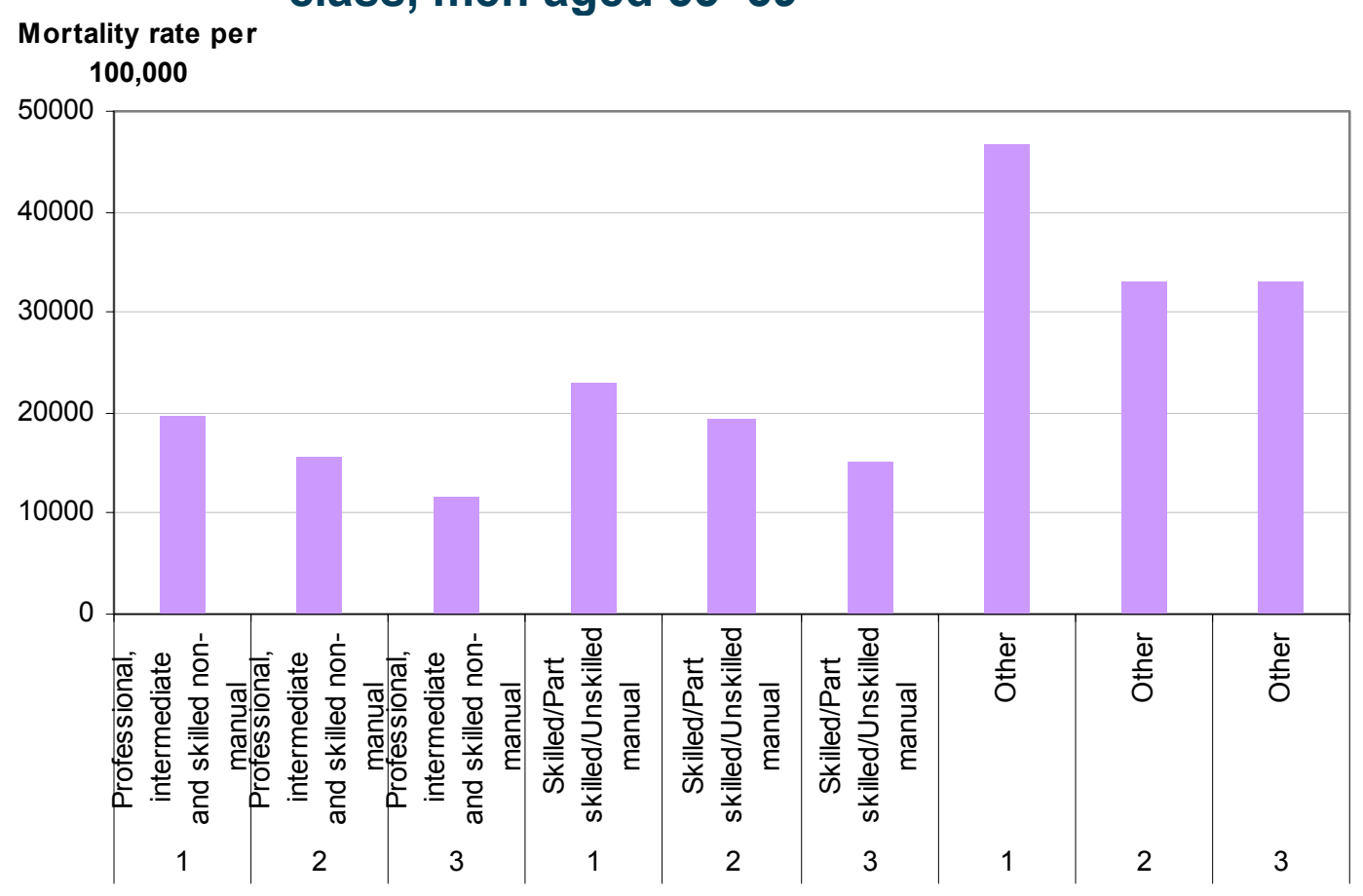

Notes: Minimum sample size: 585 men aged 55-59 at risk of dying.

'Other' includes those permanently sick, looking after family, those who are retired, in the armed forces and students.

Source: Office for National Statistics

\section{Figure $7 \mathrm{~b} \quad$ ONS LS standardised aggregated mortality rates by social class, women aged 55-59}

\section{Mortality rate per}

100,000

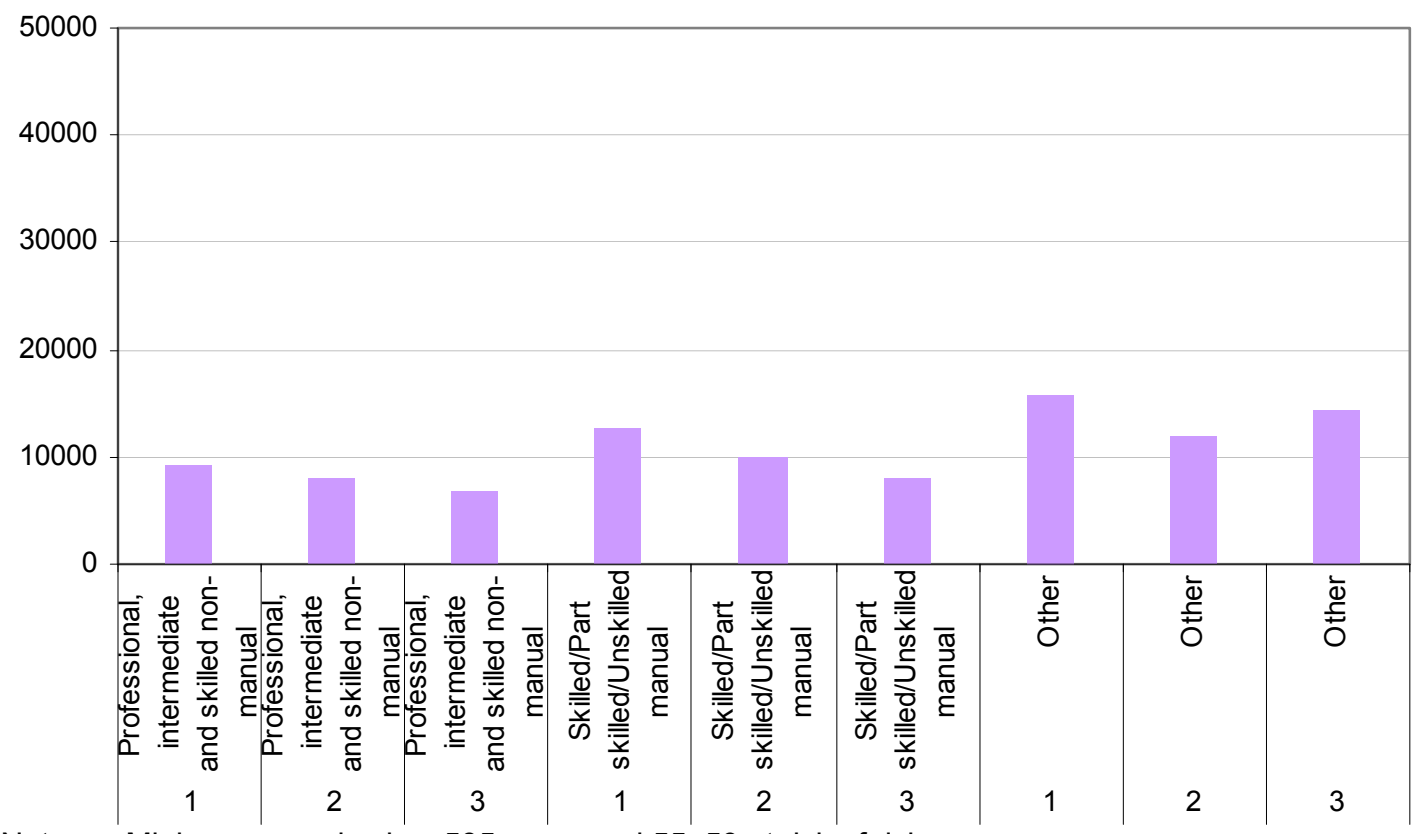

Notes: Minimum sample size: 585 men aged 55-59 at risk of dying.

'Other' includes those permanently sick, looking after family, those who are retired, in the armed forces and students.

Source: Office for National Statistics 


\section{Education level}

Tables $\mathbf{8 a}$ and $\mathbf{8 b}$ show that each successive cohort experienced an increase in the percentage with 'Higher degree, degree or equivalent' and also 'Other qualification level'. This is true for men and for women. Increased education level is associated with lower mortality (Figures $\mathbf{8 a}$ and $\mathbf{8 b}$ ). This is to be expected as having a higher education level is associated with being in the professional and intermediate social classes, which is in turn associated with lower levels of mortality ${ }^{17}$.

\section{Table 8a Percentage distribution of ONS LS members by education level, men aged 55-59}

\begin{tabular}{crrrrrrr}
\hline Cohort & Higher degree, degree & \multicolumn{2}{c}{$\begin{array}{c}\text { Other qualification level, } \\
\text { e.g A-level or equiv. }\end{array}$} & $\begin{array}{c}\text { No qualifications/ } \\
\text { None stated }\end{array}$ & \multicolumn{2}{c}{$\begin{array}{c}\text { Total } \\
\text { (number) }\end{array}$} \\
\cline { 2 - 6 } & Percentage & $\begin{array}{r}\text { Percentage } \\
\text { point } \\
\text { change }\end{array}$ & Percentage & $\begin{array}{c}\text { Percentage } \\
\text { point change }\end{array}$ & Percentage & $\begin{array}{r}\text { Percentage } \\
\text { point } \\
\text { change }\end{array}$ & \\
\hline $\mathbf{1}$ & 4 &.. & 7 &.. & 89 &.. & $100(23,371)$ \\
$\mathbf{2}$ & 7 & 3 & 9 & 2 & 84 & -5 & $100(24,365)$ \\
$\mathbf{3}$ & 10 & 3 & 17 & 8 & 74 & -10 & $100(24,878)$ \\
\hline
\end{tabular}

Source: Office for National Statistics

\section{Table $8 \mathrm{~b} \quad$ Percentage distribution of ONS LS members by education level, women aged 55-59}

\begin{tabular}{|c|c|c|c|c|c|c|c|}
\hline \multirow[t]{2}{*}{ Cohort } & \multicolumn{2}{|c|}{ Higher degree, degree } & \multicolumn{2}{|c|}{$\begin{array}{l}\text { Other qualification level, } \\
\text { e.g A-level or equiv. }\end{array}$} & \multicolumn{2}{|c|}{$\begin{array}{l}\text { No qualifications/ } \\
\text { None stated }\end{array}$} & \multirow[t]{2}{*}{$\begin{array}{r}\text { Total } \\
\text { (number) }\end{array}$} \\
\hline & Percentage & $\begin{array}{r}\text { Percentage } \\
\text { point change }\end{array}$ & Percentage & $\begin{array}{r}\text { Percentage } \\
\text { point change }\end{array}$ & Percentage & $\begin{array}{r}\text { Percentage } \\
\text { point change }\end{array}$ & \\
\hline 1 & 1 & .. & 6 & .. & 93 & .. & $100(23,371)$ \\
\hline 2 & 2 & 2 & 8 & 2 & 90 & -3 & $100(24,365)$ \\
\hline 3 & 4 & 2 & 16 & 8 & 81 & -9 & $100(24,878)$ \\
\hline
\end{tabular}

Source: Office for National Statistics 
Figure $8 \mathrm{a}$ ONS LS standardised aggregated mortality rates by education level, men aged 55-59

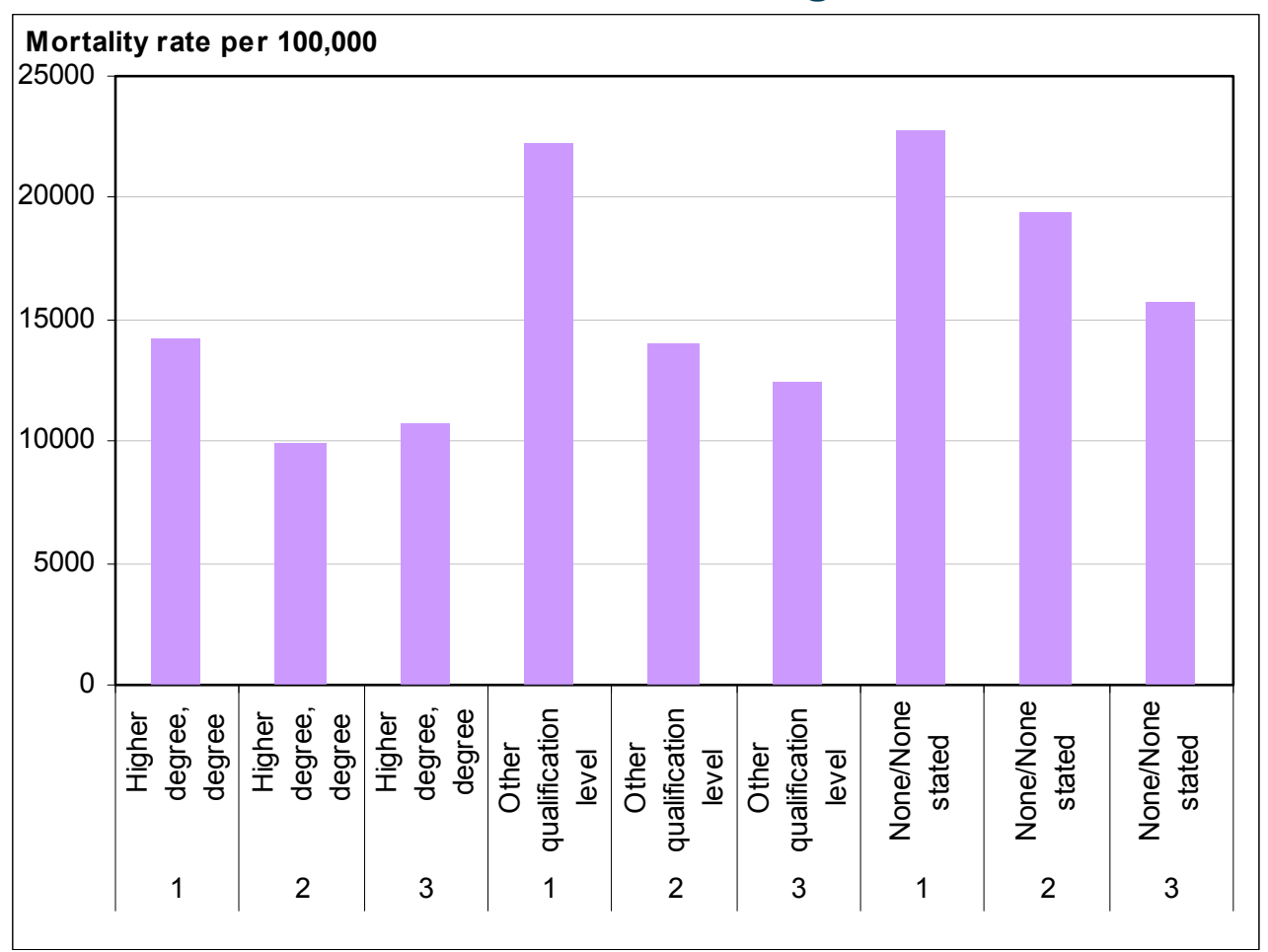

Note: Minimum sample size: 882 men aged 55-59 at risk of dying.

Source: Office for National Statistics

Figure 8b ONS LS standardised aggregated mortality rates by education level, women aged 55-59

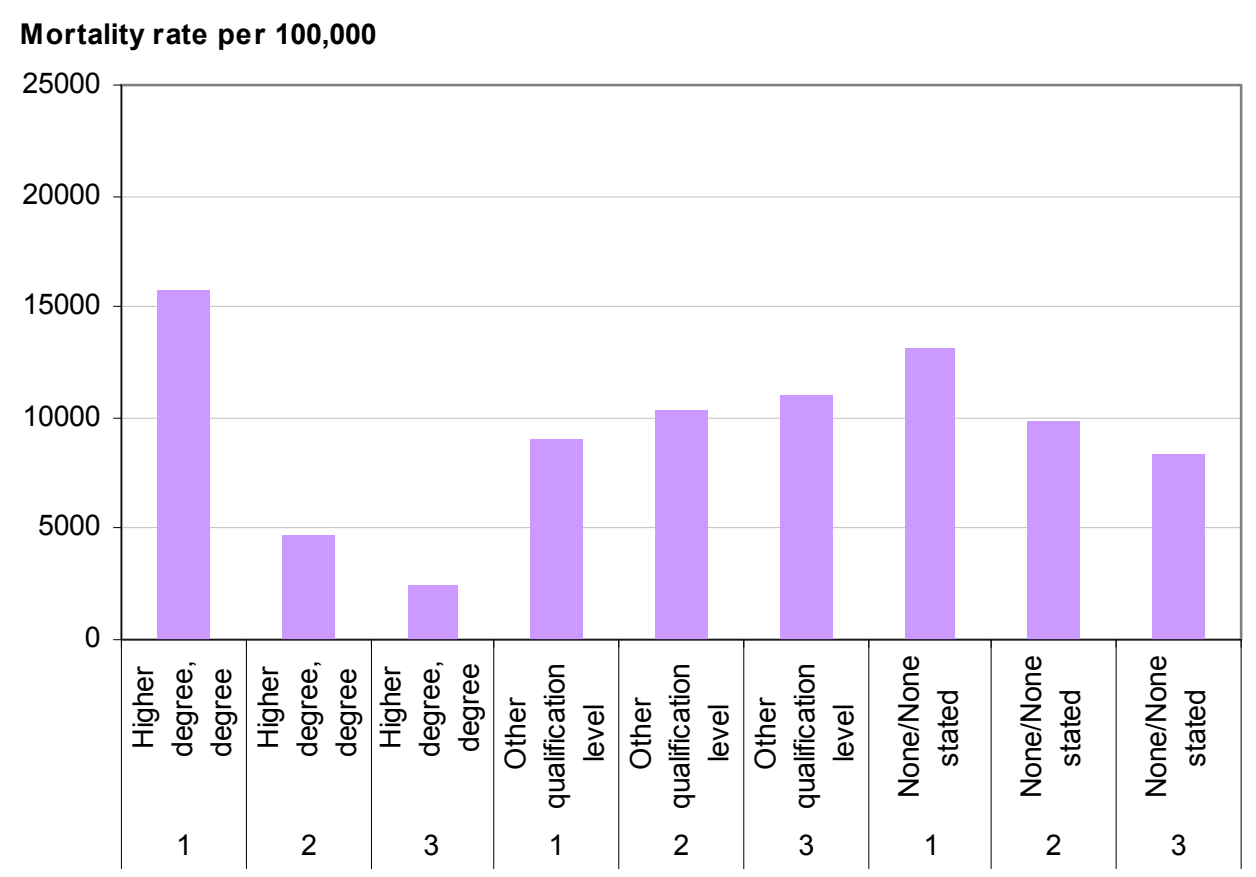

Note: Minimum sample size: 190 women aged 55-59 at risk of dying.

Source: Office for National Statistics 


\section{Tenure}

Tables $9 a$ and 9 b show an increase in owner occupiers with each successive cohort. Figures $9 a$ and $9 \mathrm{~b}$ show that ONS LS mortality rates for men and women aged 55 to 59 who were 'owner occupiers' were consistently lower than those for 'non-owner occupiers'. The link between housing tenure and mortality is well established: Fox and Goldblatt (1982) and Filakti and Fox (1995) have shown that owner occupiers have lower mortality rates than non-owner occupiers when standardised for age and sex ${ }^{18,19}$. Figures $9 a$ and $9 b$ show that ONS LS mortality rates for men and women aged 55 to 59 decreased for 'owner occupiers' with each successive cohort. However, the mortality rate rose for 'non-owner occupiers' between cohorts 2 and 3. The 1980 Housing Act gave five million council house tenants in England and Wales the right to buy their property from their local authority. Those who could afford to buy purchased their properties in the early-mid 1980s, 'promoting' them to the ranks of 'owner occupier', and so reducing the population of 'non-owner occupiers' to represent mainly those who could not afford to buy their property. It is, therefore, likely that the 'non-owner occupiers' in cohort 3 had higher mortality than the corresponding group in cohort 2, at least partly as a result of this group becoming more selected towards those unemployed, poor or sick.

\section{Table 9a Percentage distribution of ONS LS members by tenure, men aged 55-59}

\begin{tabular}{lrrrrr}
\hline Cohort & $\begin{array}{r}\text { Owner } \\
\text { occupier }\end{array}$ & $\begin{array}{r}\text { Percentage } \\
\text { point } \\
\text { change }\end{array}$ & $\begin{array}{r}\text { Not } \\
\text { owner } \\
\text { occupier }\end{array}$ & $\begin{array}{r}\text { Percentage } \\
\text { point } \\
\text { change }\end{array}$ & $\begin{array}{r}\text { Total } \\
\text { (Number) }\end{array}$ \\
\hline $\mathbf{1}$ & 51 &.. & 49 &.. & $100(23,371)$ \\
$\mathbf{2}$ & 63 & 12 & 37 & -12 & $100(24,365)$ \\
$\mathbf{3}$ & 81 & 18 & 19 & -18 & $100(24,878)$ \\
\hline
\end{tabular}

Source: Office for National Statistics

\section{Table 9b Percentage distribution of ONS LS members by tenure, women aged 55-59}

\begin{tabular}{lrrrrr}
\hline Cohort & $\begin{array}{r}\text { Owner } \\
\text { occupier }\end{array}$ & $\begin{array}{r}\text { Percentage } \\
\text { point } \\
\text { change }\end{array}$ & $\begin{array}{r}\text { Not } \\
\text { owner } \\
\text { occupier }\end{array}$ & $\begin{array}{r}\text { Percentage } \\
\text { point } \\
\text { change }\end{array}$ & $\begin{array}{r}\text { Total } \\
\text { (Number) }\end{array}$ \\
\hline $\mathbf{1}$ & 51 &.. & 49 &.. & $100(25,745)$ \\
$\mathbf{2}$ & 62 & 11 & 38 & -11 & $100(25,248)$ \\
$\mathbf{3}$ & 80 & 18 & 20 & -18 & $100(25,243)$ \\
\hline
\end{tabular}

Source: Office for National Statistics 


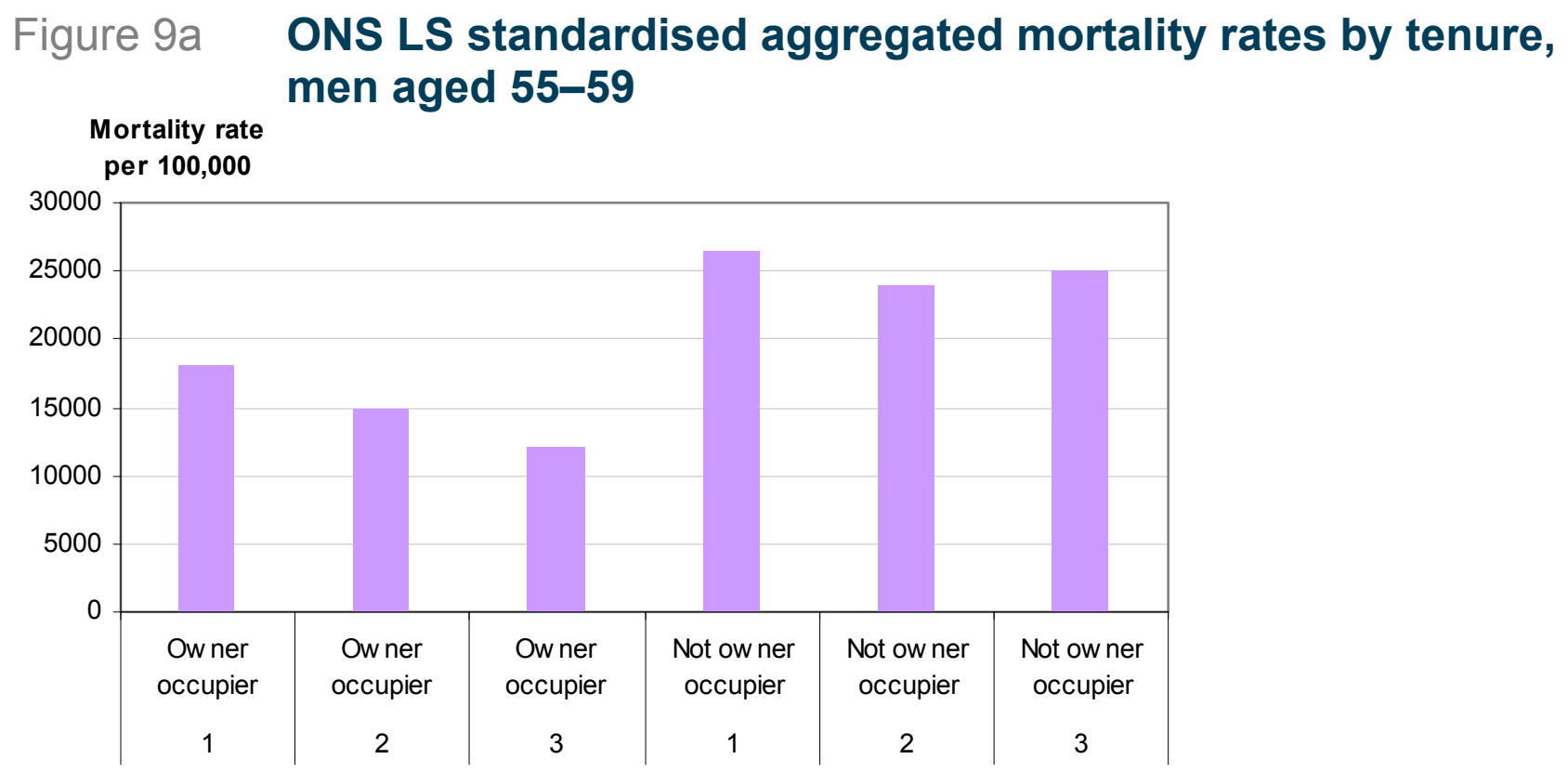

Note: Minimum sample size: 3,828 men aged 55-59 at risk of dying.

Source: Office for National Statistics Figure 9b ONS LS standardised aggregated mortality rates by tenure,
women aged 55-59

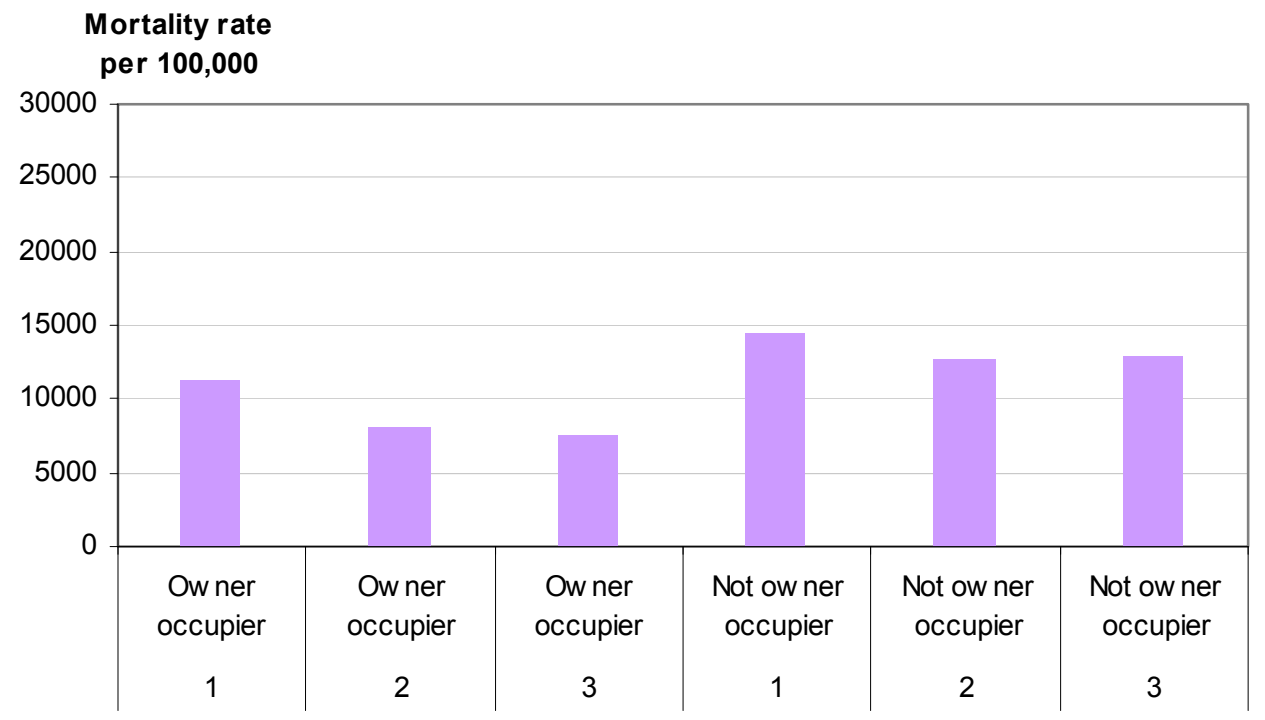

Note: Minimum sample size: 3959 women aged 55-59 at risk of dying.

Source: Office for National Statistics

\section{Quantifying the effects of change in composition verses change in mortality by characteristic}

A standardised number of deaths can be produced by applying the standardised mortality rates to the population at risk for each cohort and the change between the cohorts examined. Note that the population here is the population at risk of dying in the period concerned, excluding those that died within five years of the Census. Thus the population numbers are lower than shown in the earlier tables, and therefore the distributions slightly different. 
A crude decomposition of how much the overall mortality improvement is being driven by a change in the size and composition of the population by socio-economic group, and by changes in mortality rates of the subgroups chosen, can be obtained by:

(a) applying the mortality rates in cohort $y$ to the population distribution for cohort $y+1$ uncontrolled to the size of cohort y;

(b) applying the mortality rates in cohort y to the population distribution for cohort $y+1$ controlled to the size of cohort y; and,

(c) applying the mortality rates of cohort $y+1$ to the population of cohort $y$.

These three calculations will not produce the exact overall change as there are interactions between the rates and the populations. Also the populations are not standardised by single age for their characteristics. However, they do provide an indication of the main driver (mortality change or population size/composition change) for each of the socio-demographic characteristics examined. Table 10 shows the changes decomposed between cohort 1 and cohort 2 and between cohorts 2 and 3. A comparison can then be made between the change in the overall number of standardised deaths and the number resulting from applying the standardised mortality rates to the population.

So, for example, for male marital status between cohort 1 and cohort 2 we first compute the number of standardised deaths by applying the mortality rates by marital status for cohort 1 to the population in cohort 1 and similarly the mortality for cohort 2 to the population for cohort 2; see Table 10 cohort 1 to cohort 2 section, marital status column, rows (i) and (ii). We then try to decompose the change of 1,144 shown in row (iii) by first applying the cohort 1 mortality by marital status to the cohort 2 population: this will cover both the change in distribution and the change in size of the population. We then apply the cohort 1 mortality to the cohort 2 population distribution controlled to the size of the cohort 1 population to remove the effect of change in size. Finally, we apply the cohort 2 mortality to the cohort 1 population to give a measure of the change due to mortality. We see that the main driver appears to be mortality improvement (-916 deaths); when the population size effect is removed the composition effect would actually suggest a slight worsening in mortality.

Any conclusions drawn from the crude analysis shown in Table 10 are tentative, but the results suggest that between cohort 1 and cohort 2 there were reductions in mortality that resulted mainly from the changing mortality (row $(x)$ cohort 1 to cohort 2). Population composition effects also show small positive effects for women, but overall mortality is more dominant than composition change.

Between cohort 2 and cohort 3 reductions in standardised deaths are almost entirely resulting from the change in mortality. Population size and composition appeared to have much less of an effect; indeed for some variables (male and female marital status and economic position; male social class) there is some evidence that, other things being equal, the changes in population composition would have made mortality worse. 


\section{Table 10a Decomposition of population change and mortality change between cohorts, men}

\section{Change Cohort 1 to Cohort 2}

(i) Cohort 1 Overall Standardised deaths

(ii) Cohort 2 Overall Standardised deaths

(iii) Difference

Standardised deaths if applying

(iv) cohort 1 mortality and cohort 2 population cohort 1 mortality to cohort 2 with population controlled

(v) to cohort 1 size

(vi) cohort 2 mortality and cohort 1 population

$\begin{array}{rrrrr}\begin{array}{r}\text { Marital } \\ \text { status }\end{array} & \begin{array}{l}\text { Economic } \\ \text { position }\end{array} & \text { Education } & \begin{array}{l}\text { Social } \\ \text { class }\end{array} & \text { Tenure } \\ 4,669 & 4,675 & 4,677 & 4,675 & 4,669 \\ 3,525 & 3,540 & 3,528 & 3,529 & 3,524 \\ & & & & \\ -1,144 & -1,135 & -1,148 & -1,146 & -1,144 \\ & & & & \\ 4,368 & 4,555 & 4,289 & 4,317 & 4,084 \\ & & & & \\ 4,711 & 4,913 & 4,626 & 4,656 & 4,405 \\ 3,753 & 3,559 & 3,889 & 3,840 & 4,085 \\ & & & & \\ -301 & -121 & -387 & -358 & -585 \\ 42 & 237 & -50 & -19 & -264 \\ -343 & -358 & -337 & -339 & -321 \\ & & & & -584 \\ -916 & -1,116 & -787 & -834 & -1,168 \\ & & & & \end{array}$

\section{Change Cohort 2 to Cohort 3}

(i) Cohort 2 Overall Standardised deaths

(ii) Cohort 3 Overall Standardised deaths

(iii) Difference

Standardised deaths if applying

(iv) cohort 2 mortality and cohort 3 population
cohort 2 mortality to cohort 3 with population controlled

(v) to cohort 2 size

(vi) cohort 3 mortality and cohort 2 population

Change due to population size and

(vii) (iv) - (i) composition

(viii) (v) - (i)

Change due to population composition

(ix) (vii) - (viii)

Change due to population size

(x) (vi) - (i)

Change due to mortality improvement

(viii)+(ix)+(x)

3,725

4,084

3,530

3,707

3,354

3,871

3,930

3,397

3,567

2,909

2,762

3,227

3,247

$\begin{array}{rrrrr}199 & 544 & 2 & 178 & -170 \\ 346 & 390 & -132 & 38 & -297 \\ -147 & 155 & 134 & 140 & 127 \\ -744 & -955 & -619 & -767 & -277 \\ -545 & -411 & -617 & -589 & -447\end{array}$

Notes: Numbers shown are numbers of deaths resulting from the application of standardised mortality rates to populations.

Numbers may not sum due to rounding. 


\section{Table 10b Decomposition of population change and mortality change between cohorts, women}

\section{Change Cohort 1 to Cohort 2}

(i) Cohort 1 Overall Standardised deaths

(ii) Cohort 2 Overall Standardised deaths

(iii) Difference

Standardised deaths if applying

(iv) cohort 1 mortality and cohort 2 population cohort 1 mortality to cohort 2 with population controlled

(v) to cohort 1 size

(vi) cohort 2 mortality and cohort 1 population

(vii) (iv) - (i)

(viii) (v) - (i)

(ix) (vii) - (viii)

Change due to population size and composition

Change due to population composition

Change due to population size

(x) (vi) - (i)

Change due to mortality improvement

(viii)+(ix)+(x)

\section{Change Cohort 2 to Cohort 3}

(i) Cohort 2 Overall Standardised deaths

(ii) Cohort 3 Overall Standardised deaths

(iii) Difference

Standardised deaths if applying

(iv) cohort 2 mortality and cohort 3 population cohort 2 mortality to cohort 3 with population controlled

(v) to cohort 2 size

(vi) cohort 3 mortality and cohort 2 population

Change due to population size and

(vii) (iv) - (i) composition

(viii) (v) - (i)

Change due to population composition

(ix) (vii) - (viii)

Change due to population size

(x) (vi) - (i)

Change due to mortality improvement

(viii)+(ix)+(x)
Marital
status

Economic position

2,974

1,980

$-994$

2,983

1,978

$-1,005$

2,573

2,559

2,575

2,473

2,964

2,216

4,711

2,948

2,281

2,967

2,340

$-401$

$-10$

$-391$

$-709$

$-1,110$

$$
-424
$$

$-35$

$-389$

$-768$

$-1,192$

Marital

1,980

1,742

$-404$

$-12$

$-503$

$-127$

$-391$

$-376$

$-698$

$-636$

$-1,102$

$-1,138$
Economic

position

1,978

1,754

$-238$

$-224$
2,057

3,871

1,707
2,389

2,094

1,691
Social

class

Tenure

$1,970 \quad 1,966 \quad 1,970$

$1,746 \quad 1,745 \quad 1,750$

$-224 \quad-221$

$-221$

1,842

1,857

1,913

$\begin{array}{rrrrr}76 & 410 & 24 & -75 & -129 \\ 113 & 368 & -11 & -109 & -161 \\ -37 & 42 & 35 & 34 & 33 \\ -274 & -287 & -276 & -37 & -57 \\ -197 & 123 & -251 & -112 & -186\end{array}$

Notes: Numbers shown are numbers of deaths resulting from the application of standardised mortality rates to populations.

Numbers may not sum due to rounding. 


\section{Discussion}

The analysis of the social and demographic characteristics clearly reflects well known trends:

- the decline in marriage and rise in divorce

- increases in the number and percentage of women in employment

- increases in the number and percentage of men and women who are permanently sick

- increases in the number and percentage of men and women who are in professional and intermediate occupations

- decreases in the number and percentage of men and women in manual occupations

- increases in the number and percentage of men and women with degrees and other qualifications

- increases in home ownership

Unsurprisingly for such a complex issue, the analysis does not suggest any clear explanation for the golden cohort experiencing greater mortality improvements than the cohorts born either side. Indeed, because of the need to group data, it is more difficult to discern the golden cohort in the ONS LS data (or even the ONS mortality data grouped analogously). It does, however, indicate that changes in population composition under some of the selected broad variables (particularly marital status and economic position) may be important for mortality change when looking at a very specific age range (55-59). This may suggest that there is some element of social change and experience that assisted the generations born around 1930 to show slightly greater improvements than preceding or successive generations. Therefore, researchers may wish to look further at both changes in population composition and variation in mortality rates by that composition when considering variations between cohorts. Further work using health and cause of death data could also help determine possible drivers behind the larger mortality improvements experienced by the golden cohort.

The ONS LS has proved to be a valuable source for the analysis of socio-economic mortality differentials in many studies ${ }^{13,14,16,17,18,19}$. This article, like many others ${ }^{20}$, did not consider the cumulative effects of disadvantage in early life at later stages of life, as this would be very difficult to determine. Better nutrition and improved environmental conditions, particularly those relating to infant feeding and care, are thought to be responsible for much of the mortality improvement demonstrated in the Caselli and Capocaccia (1989) study ${ }^{21}$. It is likely that the 'golden cohort' benefited from these improvements and also avoided certain key effects that had a negative influence on life expectancy, most notably the First World War (1914-18) and the influenza pandemic (1918-21). The absence of data prior to 1971 and lack of consistent information on health throughout the decades means that we are unable to include these effects.

\section{Acknowledgements}

Thanks to all at the ONS Population and Demography Division who provided advice and feedback throughout the research. 


\section{References}

1 Murphy, M (2009) 'The Golden Generations in historical context'. British Actuarial Journal, 15, Supplement, 151-184.

2 Office for National Statistics (2008) National Population Projections 2008-based. Series PP2 No 27. Available at: www.ons.gov.uk/ons/rel/npp/national-population-projections/2008-basedreference-volume--series-pp2/2008-based-reference-volume-no--27.pdf

3 O'Connell and Dunstan (2009) 'Do cohort mortality trends emigrate?' Insights on the UK's golden cohort for a comparison with a British settler country. British Actuarial Journal. Volume 15, Supplement. Available at: www.actuaries.org.uk/sites/all/files/documents/pdf/pp091121.pdf

4 Office for National Statistics (2008) 2008-Based National Population Projections: Frequently Asked Questions. Available at: www.ons.gov.uk/ons/rel/npp/national-populationprojections/2008-based-projections/frequently-asked-questions.pdf

5 Office for National Statistics (2002) Decennial Life Tables . Available at: www.ons.gov.uk/ons/search/index.html?newquery="decennial+life+tables"

6 Charlton, J (1997) The health of adult Britain 1841-1994, Volume 1. London: Stationary Office.

7 Andreev, K and Vaupel, J (2005) Patterns of Mortality Improvement over Age and Time in Developed Countries: Estimation, Presentation and Implications for Mortality Forecasting. Available at: http://paa2005.princeton.edu/download. aspx? submissionld=51061

8 Caselli, G and Capocaccia, R (1989) 'Age, Period, Cohort and Early Mortality: An Analysis of Adult Mortality in Italy'. Population Studies, 43, pp133-153.

9 CeLSIUS (2010) The ONS Longitudinal Study Poster. Available at: www.celsius.Ishtm.ac.uk/documents/LS\%20Poster\%202010.pdf

10 CeLSIUS (2010) Online training: How to define a study population. Available at: www.celsius.Ishtm.ac.uk/modules/studypop/sp020000.html

11 Office for National Statistics (2008) The role of the NHSCR. Available at: www.ons.gov.uk/ons/about-ons/who-we-are/services/longitudinal-study/longitudinal-studyhistory-and-processes/the-role-of-the-nhs-central-register/index.html

12 Johnson, B and Blackwell, L (2007) 'Review of methods for estimating life expectancy by social class using the ONS Longitudinal Study'. Health Statistics Quarterly 35, 28-36. 
13 Clemens, T, Boyle, P and Popham, F, 2009. 'Unemployment, mortality and the problem of health-related selection: Evidence from the Scottish and England \& Wales (ONS)

Longitudinal Studies'. Health Statistics Quarterly, 43 pp. 7-13 Available at: www.ons.gov.uk/ons/rel/hsq/health-statistics-quarterly/no--43--autumn-2009/unemployment-mortality-and-the-problem-of-health-related-selection--evidence-from-the-scottish-andengland-and-wales--ons--longitudinal-studies.pdf

14 Shaw, C. 1999. '1996-based population projections by legal marital status for England and Wales'. Population Trends, 95, 23-32.

15 Lindsay, C 2003 'A century of labour market change: 1900 to 2000'. Labour Market trends, March 2003.

16 Ackinwale,B, Lynch, K, Wiggins, D, Harding, S. 2010 'Work, permanent sickness and mortality risk: a prospective cohort study of England and Wales, 1971-2006'. Journal of epidemiology and public health.

17 Goldblatt P. 'Mortality by social class, 1971-85'. Population Trends 1989; 56: 6-15.

18 Fox, A.J. and Goldblatt, P.O. (1982) 'Socio Demographic Mortality Differences, 1971-75'. OPCS LS Series No.1. London: OPCS. 1982.

19 Filakti, $\mathrm{H}$ and Fox, $\mathrm{J}$ (1995) 'Differences in mortality by housing tenure and by car access from the OPCS Longitudinal Study'. Population Trends, 81 Autumn 1995.

20 Caselli, G, Vallin, J, Vaupel, JW and Yashin, A (1987) 'Age-specific mortality trends in France and Italy since 1900: Period and Cohort effects'. European Journal of Population, 3, 33-60.

21 McKeown, T (1976) The Modern Rise of Population. Edward Arnold. 